\title{
Glyco-Nanovesicles with Activatable Near-Infrared Probes for Real-Time Monitoring of Drug Release and Targeted Delivery
}

Shoupeng Cao, Zhichao Pei, Yongqian Xu, and Yuxin Pei*

Shaanxi Key Laboratory of Natural Products \& Chemical Biology, College of Science, Northwest A\&F University, Yangling, Shaanxi 712100, People's Republic of China

\section{Supporting Information (pages)}

1. Materials and methods S2

2. Synthesis and characterization of the compounds S3

3. UV-Vis studies of 1 S13

4. The preparation, characterization and stability of the vesicles S15

5. Analysis of Lac-SS-DCM and Dox-loaded Lac-SS-DCM by dynamic light scattering (DLS) S15

6. Critical aggregation concentration (CAC) determination and ESI-MS spectrum of the products from the reaction with GSH of 1 S16

7. The study of release profile. S17

8. Drug loading. S17.

9. The study of GSH-response by flow cytometry... S18

10. The study of targeting ability by flow cytometry S18

11. The study of real-time monitoring by flow cytometry S19

12. Cytotoxicity evaluation. S20

13. Confocal laser scanning microscopy (CLSM) S21

14. References S21 


\section{Materials and methods}

All reagents were purchased from commercial suppliers and used without further purification unless specified. Water used in this work was triple distilled. Doxorubicin hydrochloride (DOX) was purchased from Sangon Biotech. N,N-Diisopropylethylamine (DIPEA) and 4-Dimethylaminopyridine (DMAP) were purchased from Energy Chemical Reagent Co.. NMR spectra were recorded on a Bruker $500 \mathrm{MHz}$ Spectrometer with working frequencies of $500 \mathrm{MHz}$ for

${ }^{1} \mathrm{H}$ and $125 \mathrm{MHz}$ for ${ }^{13} \mathrm{C}$, respectively, in DMSO- $\mathrm{d}_{6}$ or $\mathrm{CDCl}_{3}$. The residual signals from DMSO- $\mathrm{d}_{6}$ $\left({ }^{1} \mathrm{H}: \delta 2.50\right.$ ppm; $\left.{ }^{13} \mathrm{C}: \delta 39.52 \mathrm{ppm}\right)$ or $\mathrm{CDCl}_{3}\left({ }^{1} \mathrm{H}: \delta 7.26 \mathrm{ppm} ;{ }^{13} \mathrm{C}: \delta 77.00 \mathrm{ppm}\right)$ were used as internal standards. HRMS (High Resolution Mass Spectrometer) analysis was performed on an Agilent 1290-6540 UHPLC Q-Tof-HRMS. ESI-MS analysis was performed on Thermo Fisher LCQ Fleet. SEM images were obtained using S-4800 instrument (Hitachi Ltd.) with an accelerating voltage of $10.0 \mathrm{kV}$. Negative-stained TEM images were taken on a HT7700 instrument (Hitachi Ltd., $80 \mathrm{kV}$ ). The samples for negative-stained TEM were prepared by dropping a droplet of the sample solution onto a TEM grid (copper grid, 300 meshes, coated with carbon film), immediately followed by staining with $1 \%$ sodium phosphotungstate in $\mathrm{H}_{2} \mathrm{O}$ (about $2 \mu \mathrm{L}$ ) for 5 seconds. DLS measurements were performed on a DelsaTM Nano system (Beckman Coulter, U.S.A.). UV-Vis spectra were recorded with Shimadzu 1750 UV-Visible spectrophotometer (Japan) at $298 \mathrm{~K}$. Cell culture was carried out in an incubator with a humidified atmosphere of $5 \% \mathrm{CO}_{2}$ at $37{ }^{\circ} \mathrm{C}$. 


\section{Synthesis and characterization of the compounds}

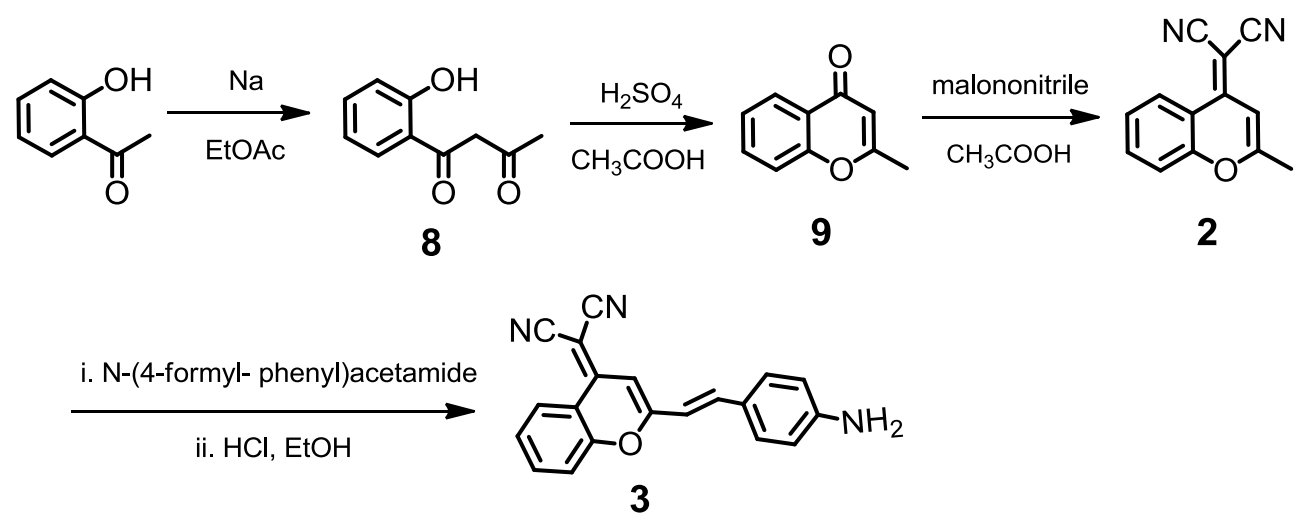

Scheme S1. Synthetic route of 3 .

Compound 8: This compound was synthesized according to the previous reported procedure. ${ }^{1}$ 1-(2-hydroxyphenyl)ethanone $(10.0 \mathrm{~g}, 73.5 \mathrm{mmol})$ was dissolved in $200 \mathrm{~mL}$ ethyl acetate, and then sodium $(8.00 \mathrm{~g}, 34 \mathrm{mmol})$ was added into the solution. The grayish-green solid was filtered after violently stirring for $4 \mathrm{~h}$ at ambient temperature. The solid was dissolved in $100 \mathrm{~mL}$ methanol to consume the remained sodium. The solvent was evaporated under vacuum and the residue was dissolved in $100 \mathrm{~mL}$ deionized water, and then adjusted its $\mathrm{pH}$ to neutral. The aqueous solution was extracted with $200 \mathrm{~mL}$ ethyl acetate. The organic layers were combined and dried over $\mathrm{Na}_{2} \mathrm{SO}_{4}$. The filtrate was concentrated to yield the crude product of $\mathbf{8}$ as a brown solid $(6.70 \mathrm{~g}, 51 \%)$, which was directly used in the next reaction without further purification.

Compound 9: This compound was synthesized according to the previous reported procedure. ${ }^{1}$ Sulfuric acid $(4.6 \mathrm{~mL})$ was slowly added to $\mathrm{AcOH}$ solution $(70 \mathrm{~mL})$ containing compound $8(6.70 \mathrm{~g}$, $37.5 \mathrm{mmol}$ ). The mixture was refluxed for about $30 \mathrm{~min}$ and then was poured into $800 \mathrm{~mL}$ ice water, followed by adjusting its $\mathrm{pH}$ to neutral with $\mathrm{Na}_{2} \mathrm{CO}_{3}$. The aqueous solution was extracted with dichloromethane twice. The organic layers were combined and dried over $\mathrm{Na}_{2} \mathrm{SO}_{4}$. The filtrate was concentrated to yield the crude product of 9 as an acicular gray solid (4.95 g, $74 \%)$. The crude product was directly used in the next reaction without further purification.

Compound 2: This compound was synthesized according to the previous reported procedure. ${ }^{1}$ Compound 9 (4.60 g, $28.7 \mathrm{mmol})$ and malononitrile $(2.40 \mathrm{~g}, 36.2 \mathrm{mmol})$ were dissolved in $25 \mathrm{~mL}$ of acetic anhydride. The solution was refluxed for $14 \mathrm{~h}$ and then the solvent was evaporated in vacuum. Deionized water $(80 \mathrm{~mL})$ was added to the residue and the mixture was refluxed for another $0.5 \mathrm{~h}$, 
followed by extraction with methylene dichloride after cooling down to room temperature. The organic layers were combined and dried over $\mathrm{Na}_{2} \mathrm{SO}_{4}$. The filtrate was concentrated to yield the crude product, which was purified by silica column chromatography to yield Compound $\mathbf{2}$ as an orange solid (1.61 g, $27 \%) .{ }^{1} \mathrm{H}$ NMR $\left(500 \mathrm{MHz}, \mathrm{CDCl}_{3}\right), \delta$ (ppm): $8.92(\mathrm{~d}, 1 \mathrm{H}, J=8.0 \mathrm{~Hz}), 7.72(\mathrm{t}$, $1 \mathrm{H}, J=8.0 \mathrm{~Hz}), 7.52-7.47(\mathrm{~m}, 2 \mathrm{H}), 6.72(\mathrm{~s}, 1 \mathrm{H}), 2.44(\mathrm{~s}, 3 \mathrm{H})$.

Compound 3: This compound was synthesized according to the previous reported procedure. ${ }^{1}$ 2-(2-methyl-4H-chromen-4-ylidene)malononitrile $\quad(200 \mathrm{mg}, \quad 0.95 \mathrm{mmol}), \quad$ and $\mathrm{N}$-(4-formylphenyl)acetamide $(142 \mathrm{mg}, 0.88 \mathrm{mmol})$ were dissolved in toluene $(10 \mathrm{~mL})$ with piperidine $(0.5 \mathrm{~mL})$ and acetic acid $(0.5 \mathrm{~mL})$ under argon protection at room temperature. Then the mixture was refluxed for $12 \mathrm{~h}$ to give an orange precipitate. After filtration, the orange solid was refluxed in a solution of conc. $\mathrm{HCl}$ and ethanol $(2: 1, \mathrm{v} / \mathrm{v}, 100 \mathrm{~mL})$ for another $16 \mathrm{~h}$ before the $\mathrm{pH}$ of the solution was adjusted to neutral. The aqueous solution was extracted with ethyl acetate. The organic layers were combined and dried over $\mathrm{Na}_{2} \mathrm{SO}_{4}$. The filtrate was concentrated to yield the crude product, which was purified by silica column chromatography to yield 3 as a crimson solid (114 mg, $39 \%$ ). ${ }^{1} \mathrm{H}$ NMR (500 MHz, DMSO), $\delta(\mathrm{ppm}): 8.73(\mathrm{~d}, 1 \mathrm{H}, J=8.0 \mathrm{~Hz}), 7.89(\mathrm{t}, 1 \mathrm{H}, J=8.0 \mathrm{~Hz}), 7.77(\mathrm{~d}, 1 \mathrm{H}, J=8.0 \mathrm{~Hz}), 7.64(\mathrm{~d}$, $1 \mathrm{H}, J=16.0 \mathrm{~Hz}), 7.58(\mathrm{t}, 1 \mathrm{H}, J=8.0 \mathrm{~Hz}), 7.49(\mathrm{~d}, 2 \mathrm{H}, J=8.0 \mathrm{~Hz}), 7.08(\mathrm{~d}, 1 \mathrm{H}, J=16.0 \mathrm{~Hz}), 6.87(\mathrm{~s}$, $1 \mathrm{H}), 6.61(\mathrm{~d}, 2 \mathrm{H}, J=8.0 \mathrm{~Hz}), 5.99(\mathrm{~s}, 2 \mathrm{H})$.

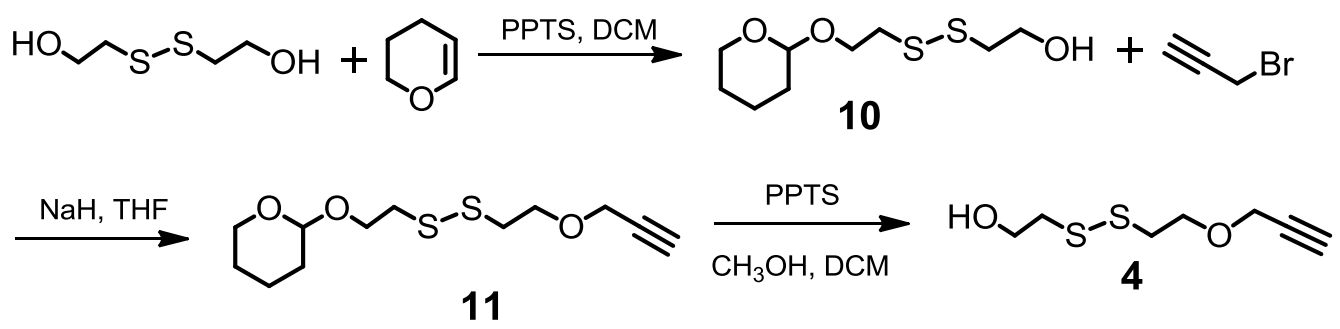

Scheme S2. Synthetic route of 4 .

Compound 10: This compound was synthesized according to the previous reported procedure. ${ }^{2} 2$, 2'-dithiodiethanol (9.8 g, $64 \mathrm{mmol})$, 3,4-dihydropyran $(2.7 \mathrm{~g}, 32 \mathrm{mmol})$ and pyridinium $\rho$-toluenesulfonate (PPTS, $33 \mathrm{mg}$ ) were dissolved in dry $\mathrm{CH}_{2} \mathrm{Cl}_{2}(60 \mathrm{~mL})$. The reaction mixture was refluxed for $12 \mathrm{~h}$ under $\mathrm{N}_{2}$. After cooling down to room temperature, the solvent was removed under vacuum and the residue was purified by column chromatography using EtOAc/Petroleum ether (2:8, v/v) as eluent. Compound 10 was isolated as a colorless oil (2.5 g, $32 \%) .{ }^{1} \mathrm{H}$ NMR (500 MHz, 
$\left.\mathrm{CDCl}_{3}\right), \delta(\mathrm{ppm}): 4.67-4.64(\mathrm{~m}, 1 \mathrm{H}), 4.08-3.93(\mathrm{~m}, 1 \mathrm{H}), 3.89-3.84(\mathrm{~m}, 3 \mathrm{H}), 3.72-3.64(\mathrm{~m}, 1 \mathrm{H})$, $3.54-3.46(\mathrm{~m}, 1 \mathrm{H}), 2.94-2.83(\mathrm{~m}, 4 \mathrm{H}), 2.42(\mathrm{br}, 1 \mathrm{H}), 1.88-1.79(\mathrm{~m}, 1 \mathrm{H}), 1.77-1.70(\mathrm{~m}, 1 \mathrm{H})$, $1.64-1.50(\mathrm{~m}, 4 \mathrm{H})$.

Compound 11: This compound was synthesized according to the previous reported procedure. ${ }^{2} \mathbf{1 0}$ $(1.9 \mathrm{~g}, 10 \mathrm{mmol})$ and $\mathrm{NaH}(1.9 \mathrm{~g}, 80 \mathrm{mmol})$ were suspended in dry $\mathrm{THF}(300 \mathrm{~mL})$ and the suspension was stirred at $0{ }^{\circ} \mathrm{C}$ for $1 \mathrm{~h}$. Propargyl bromide $(4.7 \mathrm{~g}, 40 \mathrm{mmol})$ was added dropwise (as an $80 \%$ wt. solution in toluene) and the reaction mixture was stirred at room temperature overnight. After quenching with $\mathrm{MeOH}, \mathrm{CH}_{2} \mathrm{Cl}_{2}(300 \mathrm{~mL})$ was added to the reaction mixture. The organic layer was washed with $\mathrm{H}_{2} \mathrm{O}$, and then dried over $\mathrm{Na}_{2} \mathrm{SO}_{4}$. The filtrate was concentrated to yield the crude product, which was purified by column chromatography using EtOAc/Petroleum ether (1:9, v/v) as eluent. Product 11 was isolated as a yellow oil $(1.1 \mathrm{~g}, 50 \%) .{ }^{1} \mathrm{H}$ NMR $\left(\mathrm{CDCl}_{3}, 500 \mathrm{MHz}\right), \delta(\mathrm{ppm})$ : $4.68(\mathrm{t}, J=3.5 \mathrm{~Hz}, 1 \mathrm{H}), 4.23(\mathrm{~d}, J=2.3 \mathrm{~Hz}, 2 \mathrm{H}), 4.02(\mathrm{~m}, 1 \mathrm{H}), 3.97-3.89(\mathrm{~m}, 1 \mathrm{H}), 3.84(\mathrm{t}, J=6.5$ $\mathrm{Hz}, 2 \mathrm{H}), 3.79-3.71(\mathrm{~m}, 1 \mathrm{H}), 3.62-3.51(\mathrm{~m}, 1 \mathrm{H}), 3.03-2.90(\mathrm{~m}, 4 \mathrm{H}), 2.50(\mathrm{t}, J=2.3 \mathrm{~Hz}, 1 \mathrm{H}), 1.92$ $-1.83(\mathrm{~m}, 1 \mathrm{H}), 1.79-1.83(\mathrm{~m}, 1 \mathrm{H}), 1.66-1.53(\mathrm{~m}, 4 \mathrm{H})$.

Compound 4: This compound was synthesized according to the previous reported procedure. ${ }^{2}$ Compound $11(1.1 \mathrm{~g}, 4.0 \mathrm{mmol})$ and PPTS (126 mg) were dissolved in $\mathrm{CH}_{2} \mathrm{Cl}_{2}$ and $\mathrm{MeOH}(1: 1$ in volume, $400 \mathrm{~mL}$ ). The reaction mixture was refluxed overnight under $\mathrm{N}_{2}$. After cooling down to the room temperature, the solvent was removed under vacuum and the resulting mixture was purified by column chromatography using EtOAc/Petroleum ether $(2: 8, \mathrm{v} / \mathrm{v})$ as eluent. Compound 4 was isolated as a light yellow oil $(0.5 \mathrm{~g}, 66 \%) .{ }^{1} \mathrm{H} \mathrm{NMR}\left(\mathrm{CDCl}_{3}, 500 \mathrm{MHz}\right), \delta(\mathrm{ppm}): 4.17(\mathrm{~d}, J=2.4 \mathrm{~Hz}, 2 \mathrm{H})$, $3.85(\mathrm{t}, J=5.9 \mathrm{~Hz}, 2 \mathrm{H}), 3.77(\mathrm{t}, J=6.4 \mathrm{~Hz}, 2 \mathrm{H}), 2.89(\mathrm{t}, J=6.4 \mathrm{~Hz}, 2 \mathrm{H}), 2.85(\mathrm{t}, J=5.9 \mathrm{~Hz}, 2 \mathrm{H})$, $2.46(\mathrm{t}, J=2.4 \mathrm{~Hz}, 1 \mathrm{H}), 1.99(\mathrm{t}, J=5.5 \mathrm{~Hz}, 1 \mathrm{H})$.

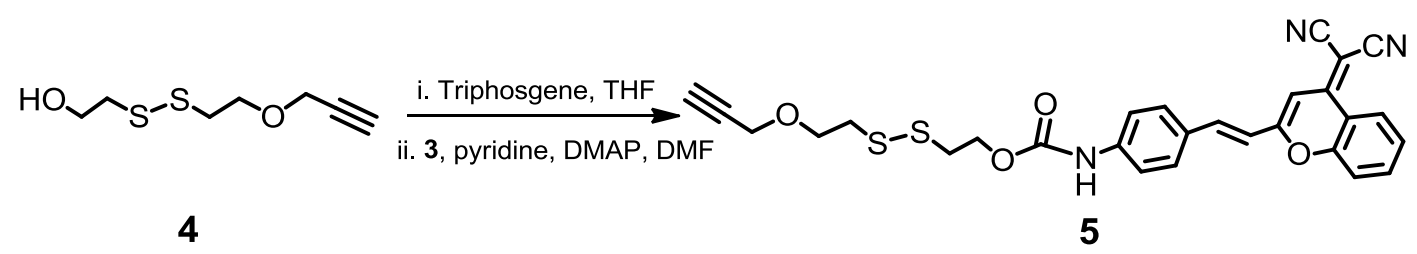

Scheme S3. Synthetic route of 5.

Compound 5: Triphosgene $(0.58 \mathrm{~g}, 1.87 \mathrm{mmol})$ was dissolved in dry THF $(5 \mathrm{~mL}))^{3,4}$ then Compound $4(0.30 \mathrm{~g}, 1.87 \mathrm{mmol})$ was added. The reaction solution was stirred for $12 \mathrm{~h}$ at room 
temperature. The solvent was evaporated under vacuum, the residue along with pyridine ( $450 \mu \mathrm{L}, 5.6$ $\mathrm{mmol}), 3$ (0.1 g, $0.28 \mathrm{mmol})$, and a catalytic amount (17 $\mathrm{mg}, 0.14 \mathrm{mmol})$ of DMAP was dissolved in dry DMF (3 mL). The solution was stirred for $14 \mathrm{~h}$ at room temperature, and the solvent was removed in vacuum. The pink residue was dissolved in $\mathrm{CH}_{2} \mathrm{Cl}_{2}(100 \mathrm{~mL})$ and washed twice with a solution of $1 \% \mathrm{HCl}$. The organic layer was dried over $\mathrm{MgSO}_{4}$, and the solvent was removed in vacuum. Purification by silica column afforded compound 5 as a pink powder $(114 \mathrm{mg}, 67 \%)$. ${ }^{1} \mathrm{H}$ NMR (500 MHz, DMSO), $\delta$ (ppm): 10.06 (s, 1H, NH), 8.75 (d, $J=8.3 \mathrm{~Hz}, 1 \mathrm{H}, \mathrm{Ph}-\mathrm{H}), 7.93$ (t, $J=$ $7.2 \mathrm{~Hz}, 1 \mathrm{H}), 7.81(\mathrm{~d}, J=8.4 \mathrm{~Hz}, 1 \mathrm{H}, \mathrm{Ph}-\mathrm{H}), 7.76-7.68(\mathrm{~m}, 3 \mathrm{H}, \mathrm{Ph}-\mathrm{H}), 7.66-7.56(\mathrm{~m}, 3 \mathrm{H}, \mathrm{Ph}-\mathrm{H}$ and alkene-H), $7.38(\mathrm{~d}, J=16.0 \mathrm{~Hz}, 1 \mathrm{H}$, alkene-H), $7.00(\mathrm{~s}, 1 \mathrm{H}, \mathrm{Ph}-\mathrm{H}), 4.38(\mathrm{t}, J=6.3 \mathrm{~Hz}, 2 \mathrm{H},-\mathrm{O}-$ $\left.\mathrm{CH}_{2}-\mathrm{CH}_{2}-\right), 4.19\left(\mathrm{~d}, \mathrm{~J}=2.4 \mathrm{~Hz}, 2 \mathrm{H},-\mathrm{O}-\mathrm{CH}_{2}-\mathrm{C}-\right), 3.72\left(\mathrm{t}, \mathrm{J}=6.3 \mathrm{~Hz}, 2 \mathrm{H},-\mathrm{O}-\mathrm{CH}_{2}-\mathrm{CH}_{2}-\right), 3.46(\mathrm{t}$, $J=2.4 \mathrm{~Hz}, 1 \mathrm{H}$, alkyne-H), $3.07\left(\mathrm{t}, J=6.3 \mathrm{~Hz}, 2 \mathrm{H},-\mathrm{O}_{-} \mathrm{CH}_{2}-\mathrm{CH}_{2}-\right), 2.98(\mathrm{t}, J=6.3 \mathrm{~Hz}, 2 \mathrm{H},-\mathrm{O}-$ $\left.\mathrm{CH}_{2}-\mathrm{CH}_{2}-\right) .{ }^{13} \mathrm{C}$ NMR (125 MHz, $\left.\mathrm{CDCl}_{3}\right), \delta$ (ppm): 158.4, 153.0, 152.9, 152.0, 141.2, 138.5, 135.3, 129.2, 126.0, 125.9, 124.6, 119.0, 118.3, 117.5, 117.1, 115.9, 106.2, 80.0, 79.2, 78.9, 78.6, 77.3, 67.3, 62.2, 59.7, 57.3, 37.6, 36.7. HRMS: $m / z$ calculated for $[\mathrm{M}+\mathrm{Na}]^{+} \mathrm{C}_{28} \mathrm{H}_{23} \mathrm{~N}_{4} \mathrm{O}_{4} \mathrm{~S}_{2}^{+}, 552.1028$, found 552.1031

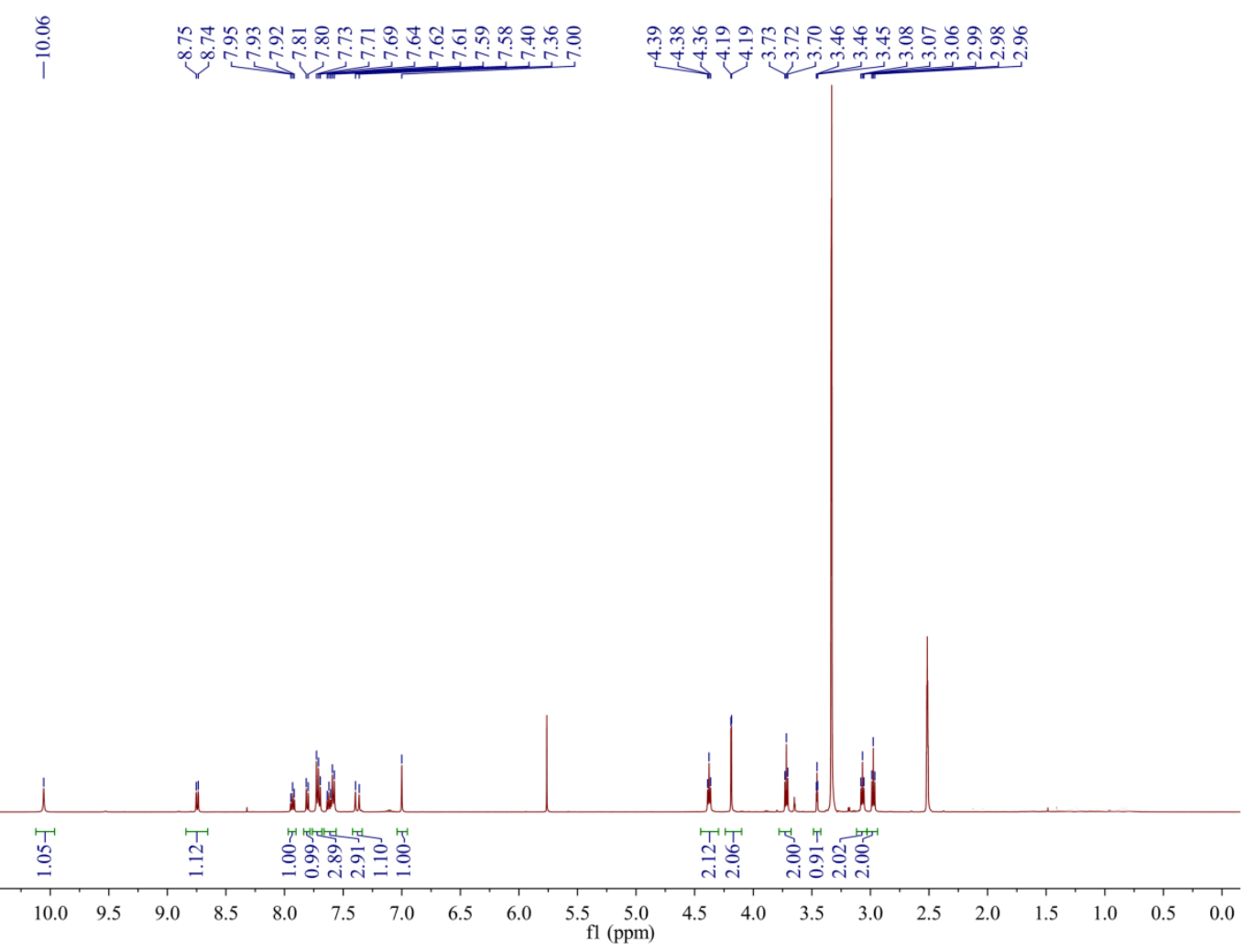

Figure S1. ${ }^{1} \mathrm{H}$ NMR spectrum of Compound 5 in DMSO. 


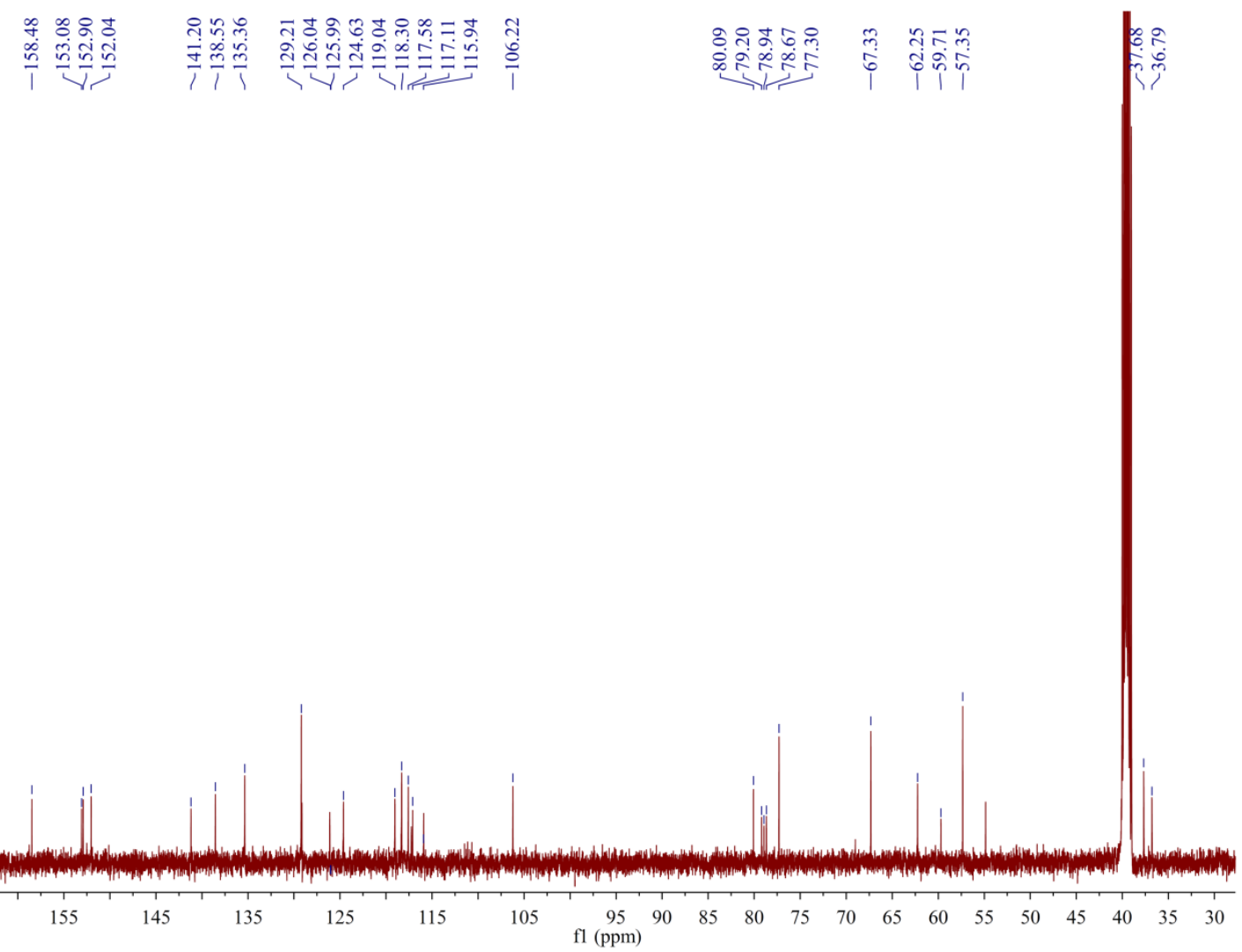

Figure S2. ${ }^{13} \mathrm{C}$ NMR spectrum of Compound $\mathbf{5}$ in DMSO.

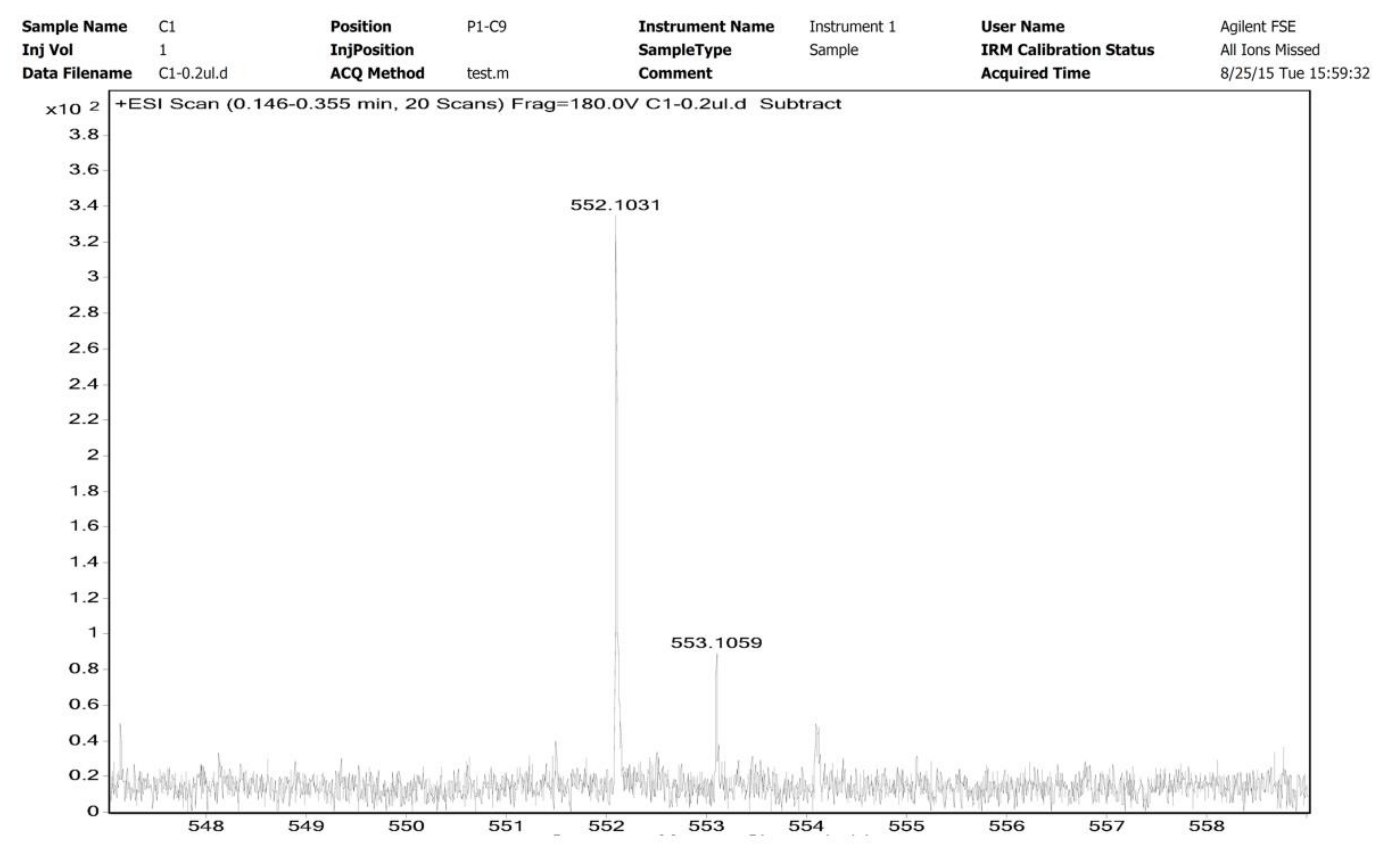

Figure S3. HRMS spectrum of Compound 5. 

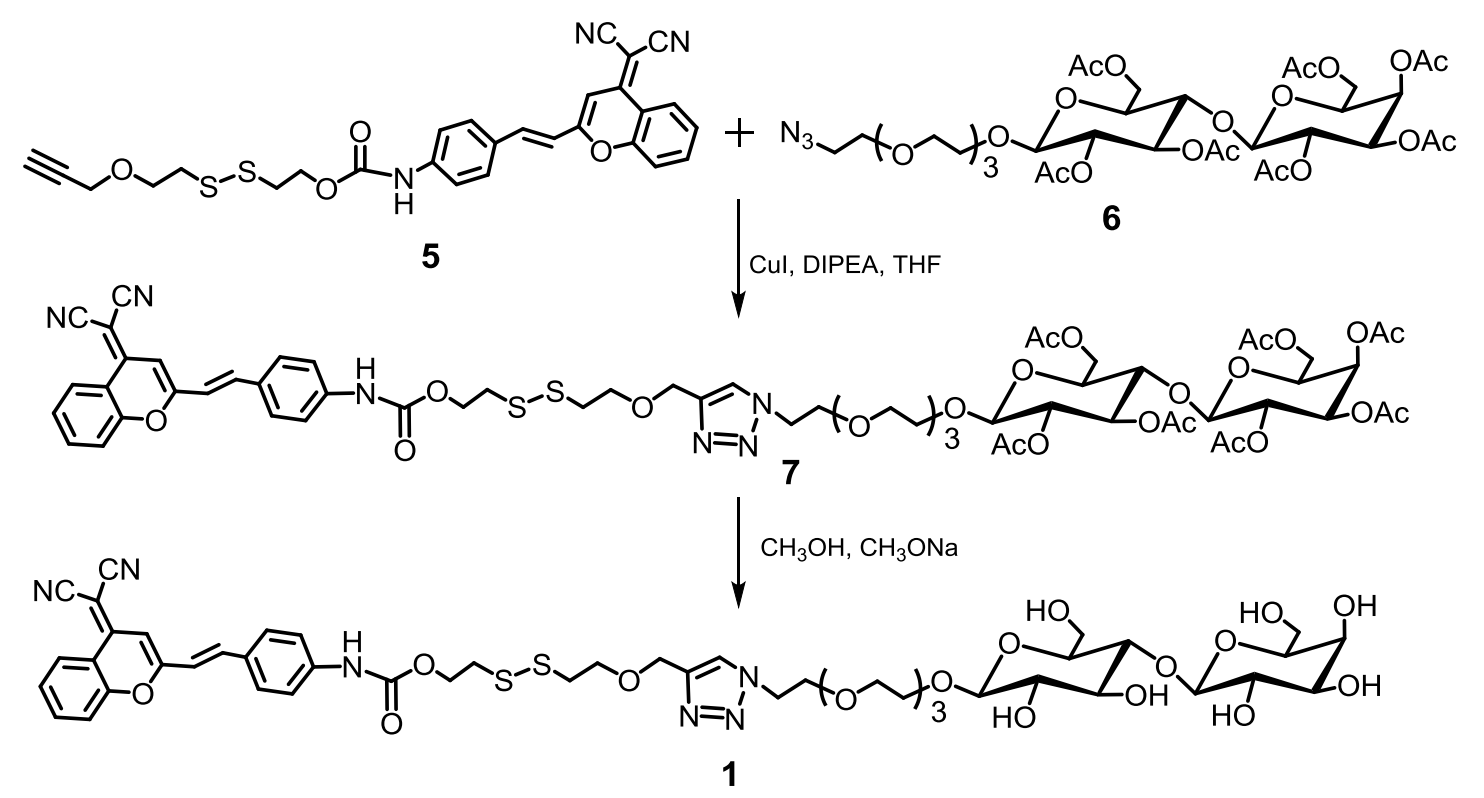

Scheme S4. Synthetic route of 1.

Compound 7: To a $10 \mathrm{~mL}$ flask were added $\mathbf{6}^{5}$ (125.5 mg, $\left.0.15 \mathrm{mmol}\right), 5(52.9 \mathrm{mg}, 0.1 \mathrm{mmol})$, and CuI (19.5 mg, $0.1 \mathrm{mmol})$. The mixture was degassed by several cycles of vacuum/ argon. Then dry THF ( $5 \mathrm{~mL})$ and DIPEA $(0.3 \mathrm{~mL})$ was injected into the flask. The reaction mixture was degassed one more time and flushed with argon. The reaction mixture was stirred at $\mathrm{rt}$ for $12 \mathrm{~h}$. Then, the solvent was evaporated in vacuum. The residue was purified by column chromatography using $\mathrm{DCM} / \mathrm{MeOH}$ (20:1, v/v) as eluent. The product 7 was isolated as reddish-brown solid (102 mg, $66 \%)$. ${ }^{1} \mathrm{H}$ NMR $\left(500 \mathrm{MHz}, \mathrm{CDCl}_{3}\right), \delta$ (ppm): 8.90 (dd, $\left.J=8.4,1.3 \mathrm{~Hz}, 1 \mathrm{H}, \mathrm{Ph}-\mathrm{H}\right), 7.85$ (s, 1H, NH), $7.79(\mathrm{~s}, 1 \mathrm{H}$, triazole-H), $7.75-7.70(\mathrm{~m}, 1 \mathrm{H}, \mathrm{Ph}-\mathrm{H}), 7.58(\mathrm{~d}, J=15.9 \mathrm{z}, 1 \mathrm{H}$, alkene-H), $7.55(\mathrm{~m}, 5 \mathrm{H}, \mathrm{Ph}-\mathrm{H}), 7.47$ - $7.42(\mathrm{~m}, 1 \mathrm{H}, \mathrm{Ph}-\mathrm{H}), 6.84(\mathrm{~s}, 1 \mathrm{H}, \mathrm{Ph}-\mathrm{H}), 6.74(\mathrm{~d}, J=15.9 \mathrm{~Hz}, 1 \mathrm{H}$, alkene-H), $5.34(\mathrm{~d}, J=3.3 \mathrm{~Hz}$, $1 \mathrm{H},-\mathrm{O}-\mathrm{CH}-\mathrm{CH}-), 5.18(\mathrm{t}, J=9.3 \mathrm{~Hz}, 1 \mathrm{H},-\mathrm{O}-\mathrm{CH}-\mathrm{CH}-), 5.09(\mathrm{dd}, J=10.4,7.9 \mathrm{~Hz}, 1 \mathrm{H},-\mathrm{O}-\mathrm{CH}-$ $\mathrm{CH}-$ ), 4.95 (dd, $J=10.4,3.4 \mathrm{~Hz}, 1 \mathrm{H},-\mathrm{O}-\mathrm{CH}-\mathrm{CH}-$ ), 4.88 (dd, $J=9.5,8.0 \mathrm{~Hz}, 1 \mathrm{H},-\mathrm{O}-\mathrm{CH}-\mathrm{CH}-$ ), $4.70\left(\mathrm{~s}, 2 \mathrm{H},-\mathrm{O}-\mathrm{CH}_{2}-\mathrm{C}-\right), 4.54\left(\mathrm{~m}, 3 \mathrm{H},-\mathrm{N}-\mathrm{CH}_{2}-\mathrm{CH}_{2}-\right.$ and $\left.-\mathrm{O}-\mathrm{CH}-\mathrm{CH}-\right), 4.48(\mathrm{~d}, \mathrm{~J}=8.0 \mathrm{~Hz}, 2 \mathrm{H}$, $\left.-\mathrm{O}-\mathrm{CH}_{2}-\mathrm{CH}-\right), 4.42\left(\mathrm{t}, \mathrm{J}=6.2 \mathrm{~Hz}, 2 \mathrm{H},-\mathrm{O}-\mathrm{CH}_{2}-\mathrm{CH}_{2}-\right), 4.16-4.04\left(\mathrm{~m}, 3 \mathrm{H},-\mathrm{O}-\mathrm{CH}_{2}-\mathrm{CH}-\right.$ and-O$\mathrm{CH}-\mathrm{CH}-$ ), $3.89-3.84\left(\mathrm{~m}, 3 \mathrm{H},-\mathrm{O}-\mathrm{CH}_{2}-\mathrm{CH}_{2}-\right.$ and $\left.-\mathrm{O}-\mathrm{CH}-\mathrm{CH}-\right), 3.82-3.76\left(\mathrm{~m}, 3 \mathrm{H},-\mathrm{O}-\mathrm{CH}_{2}-\right.$ $\mathrm{CH}_{2}-$ and $\left.-\mathrm{O}-\mathrm{CH}-\mathrm{CH}-\right), 3.72-3.67(\mathrm{~m}, 1 \mathrm{H},-\mathrm{O}-\mathrm{CH}-\mathrm{CH}-), 3.63-3.57\left(\mathrm{~m}, 12 \mathrm{H},-\mathrm{O}-\mathrm{CH}_{2}-\mathrm{CH}_{2}-\right.$ $\mathrm{O}-), 2.98\left(\mathrm{t}, J=6.2 \mathrm{~Hz}, 2 \mathrm{H},-\mathrm{O}-\mathrm{CH}_{2}-\mathrm{CH}_{2}-\right), 2.93\left(\mathrm{t}, J=6.4 \mathrm{~Hz}, 2 \mathrm{H},-\mathrm{O}-\mathrm{CH}_{2}-\mathrm{CH}_{2}-\right), 2.13(\mathrm{~s}, 3 \mathrm{H},-$ $\left.\mathrm{CO}-\mathrm{CH}_{3}\right), 2.10\left(\mathrm{~s}, 3 \mathrm{H},-\mathrm{CO}-\mathrm{CH}_{3}\right), 2.05\left(\mathrm{~s}, 3 \mathrm{H},-\mathrm{CO}-\mathrm{CH}_{3}\right), 2.03\left(\mathrm{~s}, 6 \mathrm{H},-\mathrm{CO}-\mathrm{CH}_{3}\right), 2.02(\mathrm{~s}, 3 \mathrm{H},-$ $\left.\mathrm{CO}-\mathrm{CH}_{3}\right), 1.96\left(\mathrm{~s}, 3 \mathrm{H},-\mathrm{CO}-\mathrm{CH}_{3}\right) .{ }^{13} \mathrm{C}$ NMR $\left(125 \mathrm{MHz}, \mathrm{CDCl}_{3}\right), \delta$ (ppm): 170.5, 170.4, 170.2, 
$170.1,169.9,169.7,169.2,157.8,153.1,152.9,152.4,144.7,140.6,138.5,134.7,129.7,129.1$, 126.0, 125.9, 124.2, 118.9, 118.7, 118.0, 117.3, 117.0, 115.9, 106.6, 101.2, 100.7, 76.3, 72.9, 72.8, $71.8,71.1,70.8,70.7,70.7,70.6,70.5,70.4,69.5,69.2,69.1,68.4,66.7,64.2,63.0,62.4,62.1,60.8$, 53.5, 50.9, 50.4, 38.5, 37.9, 21.0, 20.9, 20.8, 20.7, 20.6. HRMS: $\mathrm{m} / \mathrm{z}$ calculated for $[\mathrm{M}+\mathrm{H}]^{+}$ $\mathrm{C}_{62} \mathrm{H}_{74} \mathrm{~N}_{6} \mathrm{O}_{25} \mathrm{~S}_{2}{ }^{+}, 1367.4223$, found 1367.4218.

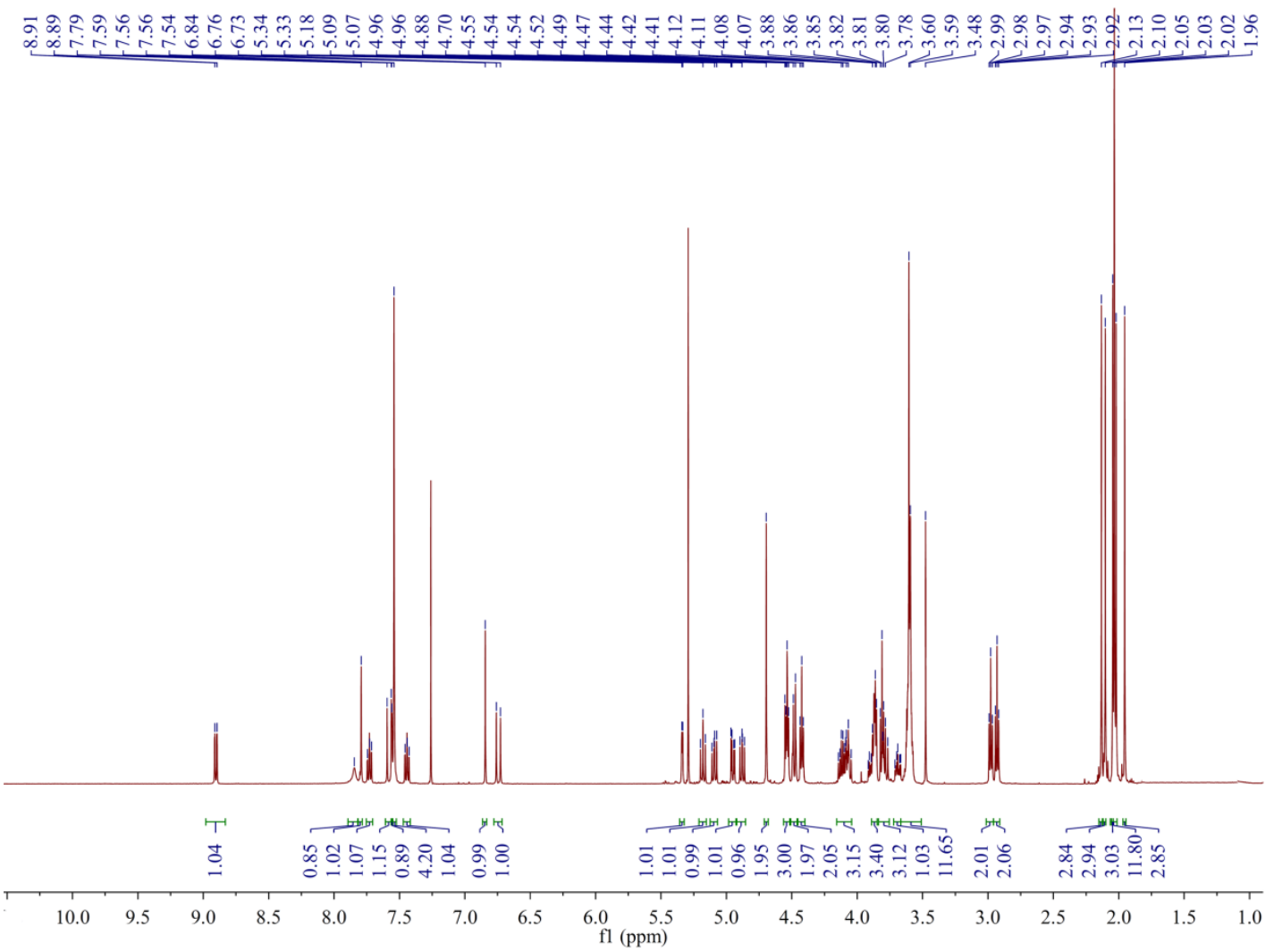

Figure S4. ${ }^{1} \mathrm{H}$ NMR spectrum of Compound 7 in $\mathrm{CDCl}_{3}$. 


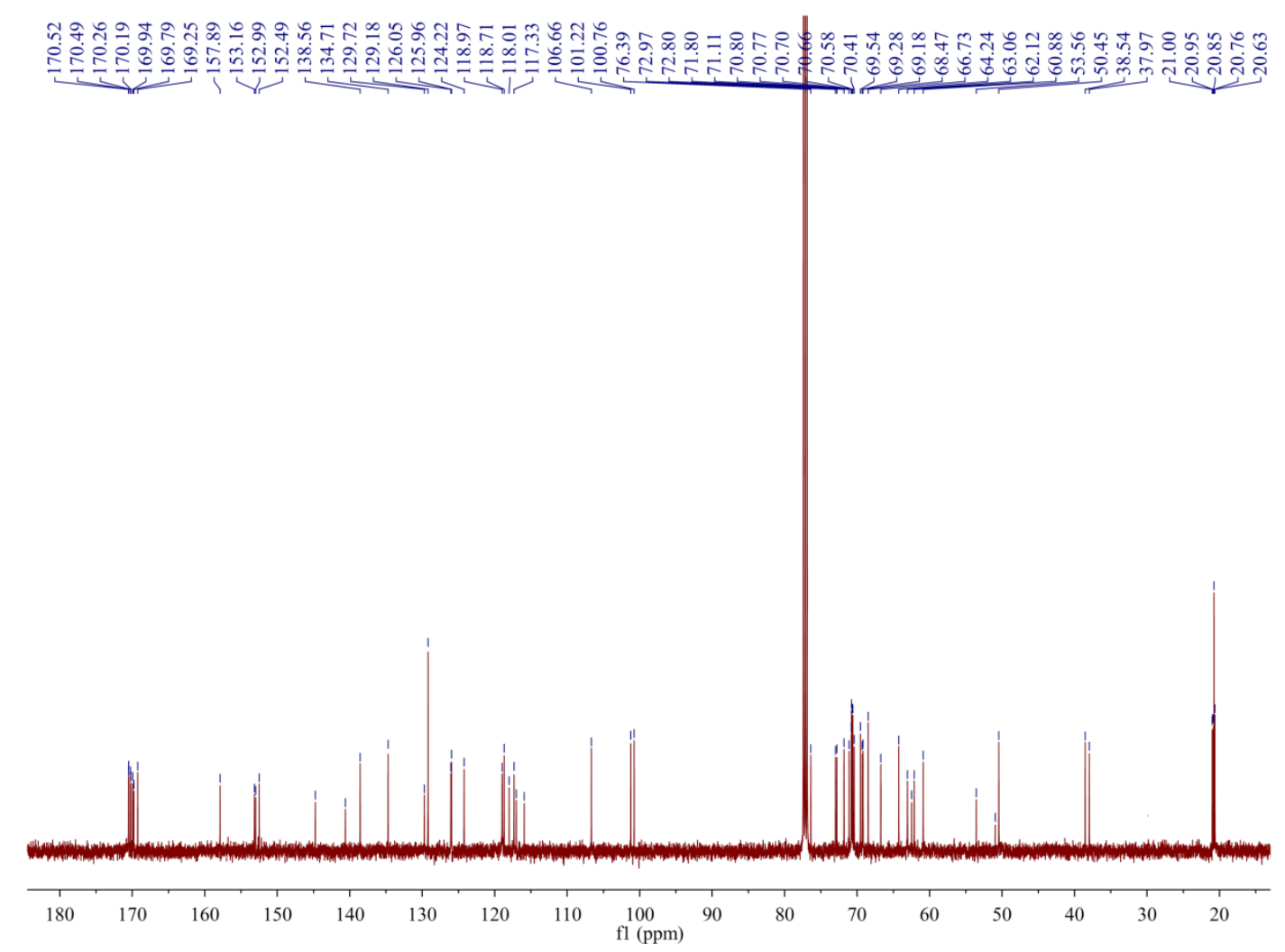

Figure S5. ${ }^{13} \mathrm{C}$ NMR spectrum of Compound 7 in $\mathrm{CDCl}_{3}$.

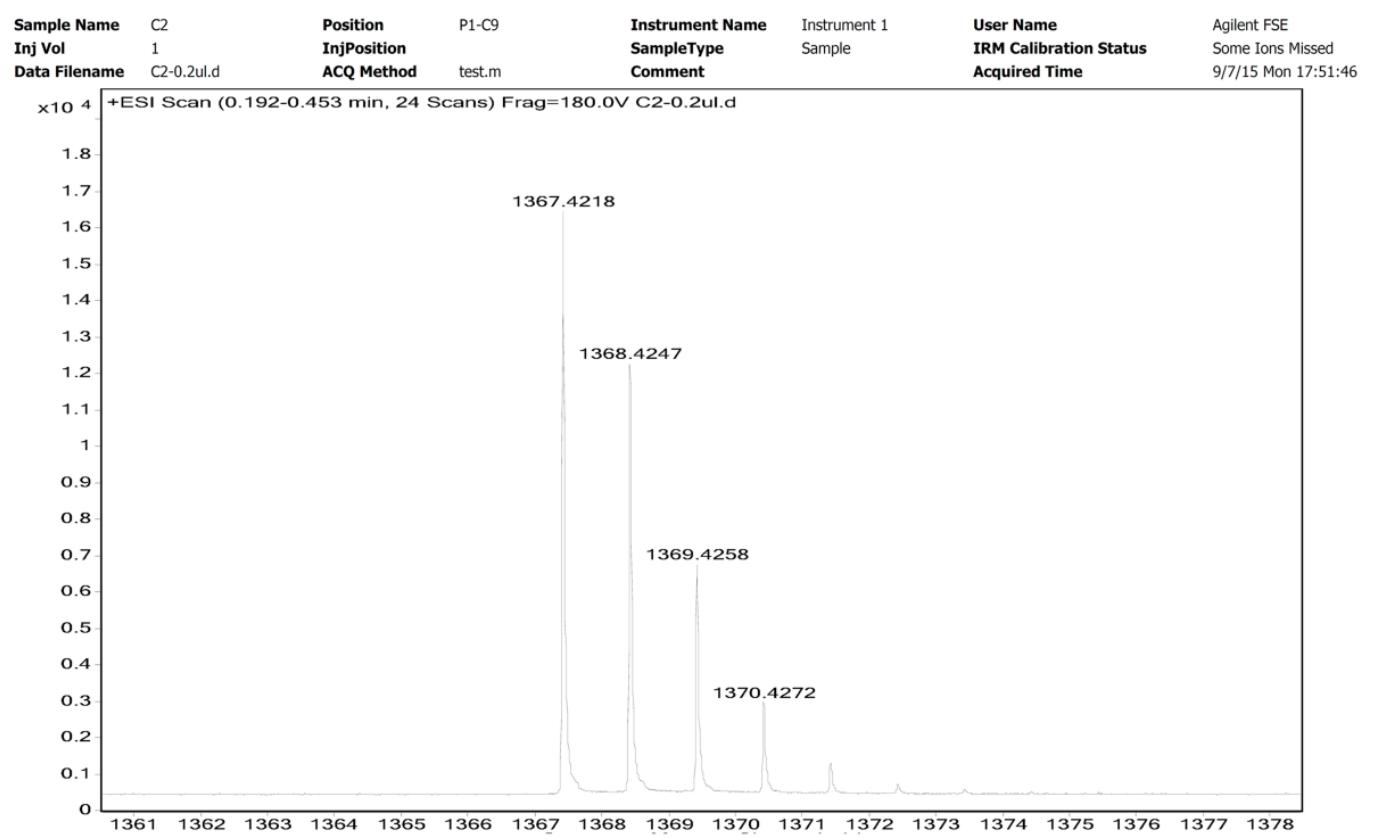

Figure S6. HRMS spectrum of Compound 7.

Compound 1: To a solution of Compound 7 (41 mg, $0.03 \mathrm{mmol})$ in dry $\mathrm{MeOH}(5 \mathrm{~mL}), \mathrm{CH}_{3} \mathrm{ONa}(1.6$ $\mathrm{mg}, 0.03 \mathrm{mmol}$ ) was added. The reaction mixture was stirred at room temperature for $12 \mathrm{~h}$. The 
solution was then neutralized by addition of ion-exchange resin (Amberlite IR $120 \mathrm{H}^{+}$) until $\mathrm{pH}=7$, filtered, and the solvent was removed under reduced pressure to give the final product of $\mathbf{1}$ as a yellow solid (30 mg, $96 \%$ ). ${ }^{1} \mathrm{H}$ NMR (500 MHz, DMSO), $\delta$ (ppm): 10.05 (s, 1H, NH), 8.77 (dd, $J=$ 8.4 Hz, 1.1 Hz, 1H, Ph-H), 8.09 (s, 1H, triazole-H), $7.98-7.92$ (m, 1H, Ph-H), 7.83 (d, J = 8.4 Hz, 1H, Ph-H), $7.76-7.71(\mathrm{~m}, 3 \mathrm{H}, \mathrm{Ph}-\mathrm{H}$ and alkene-H), $7.65(\mathrm{~d}, J=8.3 \mathrm{~Hz}, 1 \mathrm{H}, \mathrm{Ph}-\mathrm{H}), 7.61(\mathrm{t}, J=6.4$ $\mathrm{Hz}, 2 \mathrm{H}, \mathrm{Ph}-\mathrm{H}), 7.39$ (d, J = 16.0 Hz, 1H, alkene-H), 7.02 (s, $1 \mathrm{H}, \mathrm{Ph}-\mathrm{H}), 5.08$ (s, 2H, -O-CH $-\mathrm{C}-$ ), $4.76(\mathrm{~s}, 1 \mathrm{H},-\mathrm{OH}), 4.69(\mathrm{~s}, 1 \mathrm{H},-\mathrm{OH}), 4.65\left(\mathrm{t}, J=4.8 \mathrm{~Hz}, 1 \mathrm{H},-\mathrm{O}-\mathrm{CH}-\mathrm{CH}_{2}-\right), 4.59$ (s, 2H, 2-OH), $4.55\left(\mathrm{~m}, 3 \mathrm{H},-\mathrm{N}-\mathrm{CH}_{2}-\mathrm{CH}_{2}-\right.$ and $\left.-\mathrm{OH}\right), 4.51(\mathrm{~d}, J=3.4 \mathrm{~Hz}, 1 \mathrm{H},-\mathrm{O}-\mathrm{CH}-\mathrm{CH}-), 4.38(\mathrm{t}, J=6.2 \mathrm{~Hz}$, $2 \mathrm{H}, \mathrm{OH}-\mathrm{CH}-\mathrm{CH}-), 4.26-4.22(\mathrm{~m}, 2 \mathrm{H}, 2-\mathrm{OH}), 4.17\left(\mathrm{~m}, \mathrm{1H},-\mathrm{O}-\mathrm{CH}-\mathrm{CH}_{2}-\right), 4.09$ (m, 2H, OH-CH$\mathrm{CH}-), 3.92-3.86\left(\mathrm{~m}, 1 \mathrm{H},-\mathrm{O}-\mathrm{CH}-\mathrm{CH}_{2}-\right), 3.85$ (t, $\left.\mathrm{J}=5.3 \mathrm{~Hz}, 2 \mathrm{H},-\mathrm{O}-\mathrm{CH}_{2}-\mathrm{CH}_{2}\right), 3.81-3.76$ (m, $1 \mathrm{H},-\mathrm{O}-\mathrm{CH}-\mathrm{CH}-), 3.74\left(\mathrm{t}, \mathrm{J}=6.3 \mathrm{~Hz}, 2 \mathrm{H}, \mathrm{O}-\mathrm{CH}_{2}-\mathrm{CH}_{2}\right), 3.66-3.58\left(\mathrm{~m}, 6 \mathrm{H}, \mathrm{O}-\mathrm{CH}_{2}-\mathrm{CH}_{2},-\mathrm{O}-\right.$ $\mathrm{CH}-\mathrm{CH}-$ and $\mathrm{HO}-\mathrm{CH}-\mathrm{CH}-), 3.56-3.48\left(\mathrm{~m}, 12 \mathrm{H},-\mathrm{O}-\mathrm{CH}_{2}-\mathrm{CH}_{2}-\mathrm{O}-\right), 3.06\left(\mathrm{~m}, 3 \mathrm{H}, \mathrm{O}-\mathrm{CH}_{2}-\mathrm{CH}_{2}\right.$ and $\mathrm{O}-\mathrm{CH}-\mathrm{CH}-), 2.99\left(\mathrm{t}, \mathrm{J}=6.3 \mathrm{~Hz}, 2 \mathrm{H},-\mathrm{O}-\mathrm{CH}_{2}-\mathrm{CH}_{2}\right) .{ }^{13} \mathrm{C}$ NMR $\left(125 \mathrm{MHz}, \mathrm{CDCl}_{3}\right), \delta(\mathrm{ppm})$ : $158.4,153.0,152.8,152.0,143.5,141.1,138.5,135.3,131.4,129.1,129.1,128.5,126.0,124.5$, 124.2, 118.9, 118.2, 117.5, 117.1, 117.0, 115.8, 106.1, 103.7, 102.6, 80.6, 75.4, 74.9, 74.8, 73.2, 73.0, 70.5, 69.7, 69.6, 69.5, 69.4, 68.6, 68.0, 67.9, 67.7, 67.3, 63.2, 62.2, 60.5, 60.3, 49.2, 48.5, 37.8, 36.7 . HRMS: $m / z$ calculated for $[\mathrm{M}+\mathrm{H}]^{+} \mathrm{C}_{48} \mathrm{H}_{60} \mathrm{~N}_{6} \mathrm{O}_{18} \mathrm{~S}_{2}{ }^{+}, 1073.3484$, found 1073.3476 . 


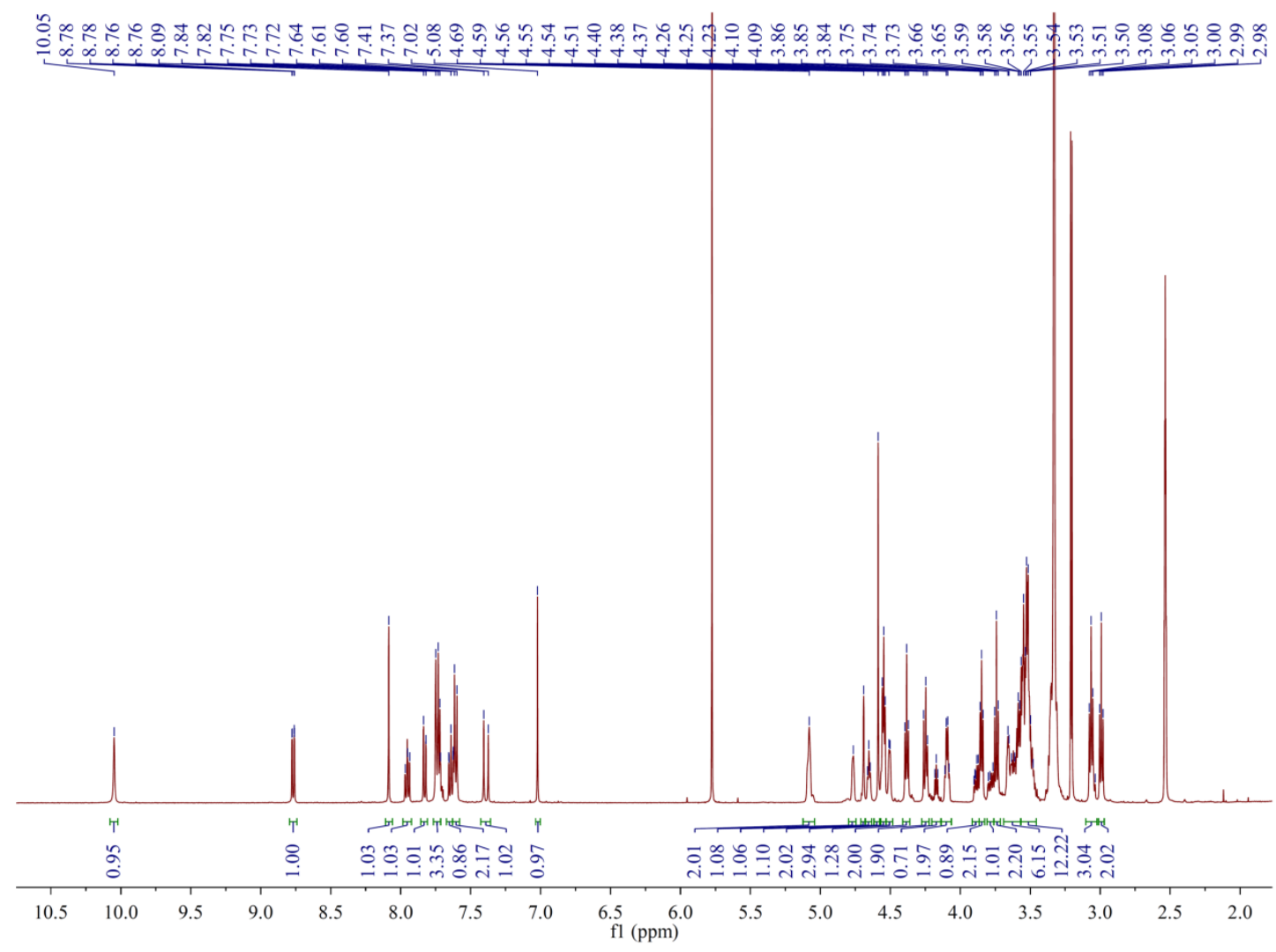

Figure S7. ${ }^{1} \mathrm{H}$ NMR spectrum of Compound $\mathbf{1}$ in DMSO.

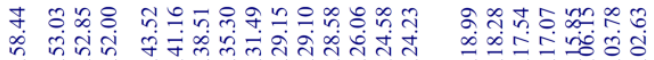

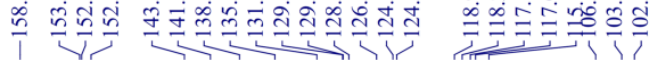

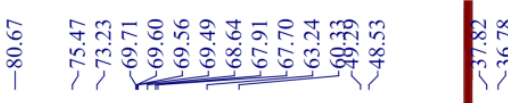

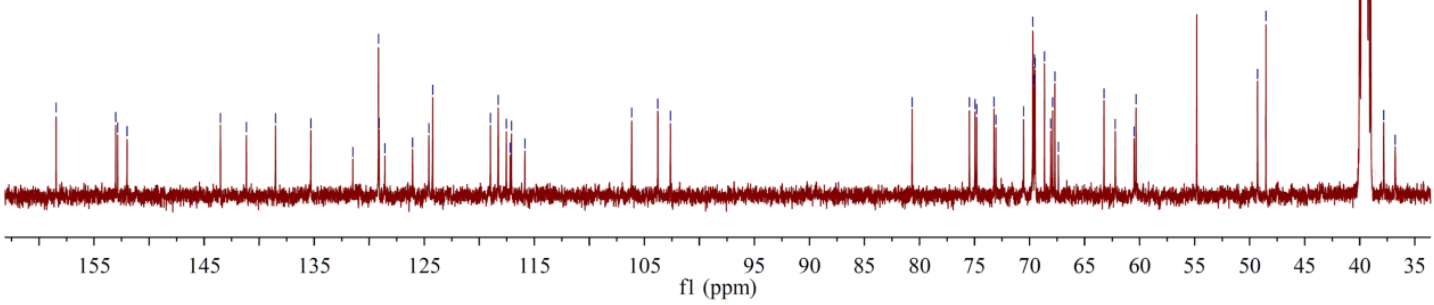

Figure S8. ${ }^{13} \mathrm{C}$ NMR spectrum of Compound $\mathbf{1}$ in DMSO. 


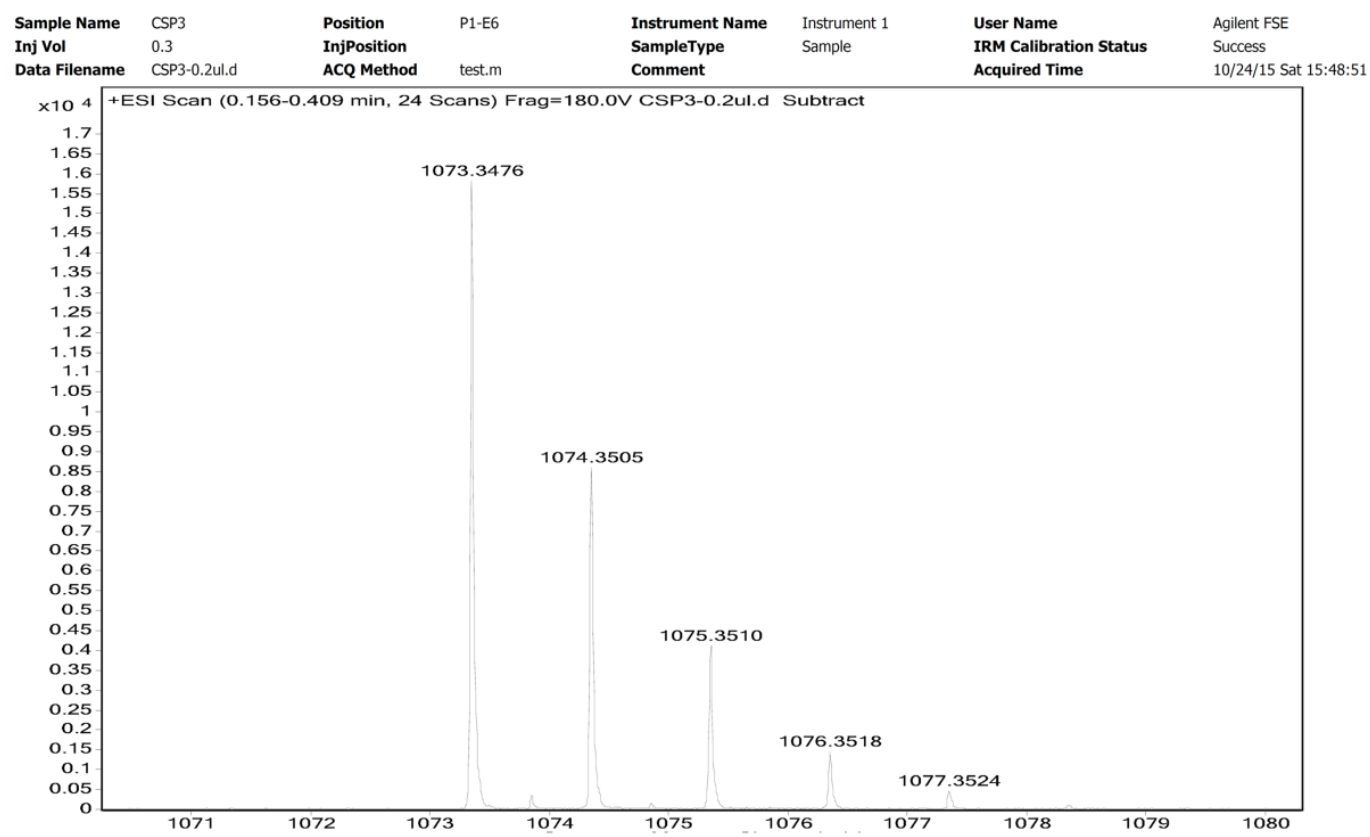

Figure S9. HRMS spectrum of Compound 1.

\section{3. $U V$-Vis studies of 1}

a)

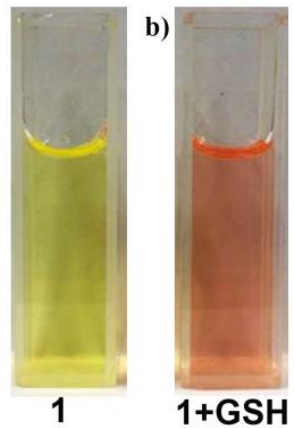

c)

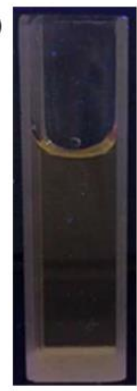

1

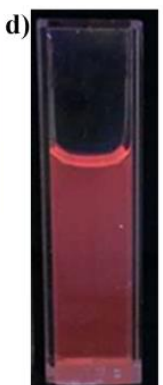

$1+\mathrm{GSH}$

Figure S10. Color change of $\mathbf{1}(10 \mu \mathrm{M})$ incubated with $2 \mathrm{mM}$ GSH in DMSO/PBS solution (50/50, $\mathrm{v} / \mathrm{v}, \mathrm{pH}=7.4,10 \mathrm{mM}$ ) for $1 \mathrm{~h}$ at $37^{\circ} \mathrm{C}$, viewed under nature light (a, b) and under UV lamp (c, d). 
a)
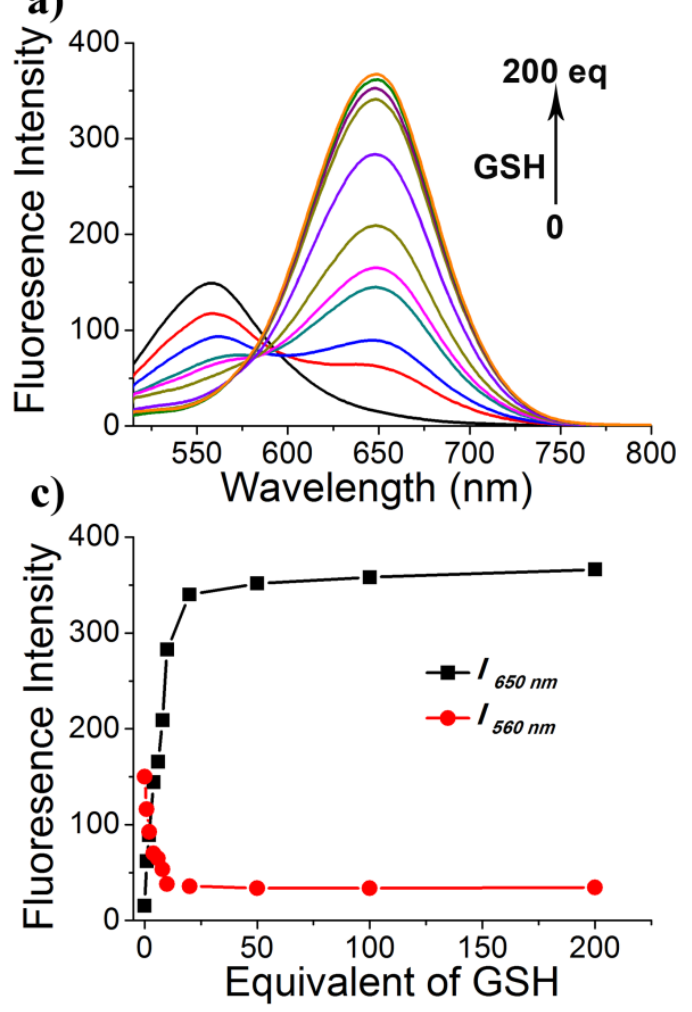

b)
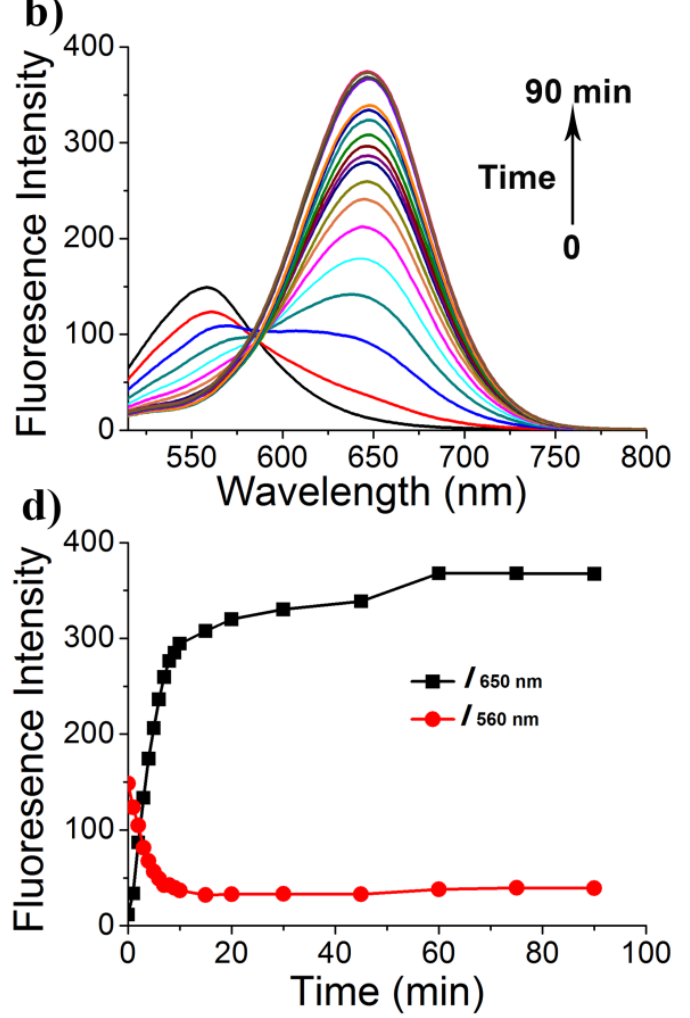

Figure S11. (a) Fluorescence intensity of 1 with increasing concentration of GSH; (b) fluorescence intensity of $1(10.0 \mu \mathrm{M})$ with increasing incubation time with GSH $(2 \mathrm{mM})$; (c) fluorescence intensity at $650 \mathrm{~nm}$ and $560 \mathrm{~nm}$ of $\mathbf{1}$ as a function of equivalent of GSH; (d) fluorescence intensity at $650 \mathrm{~nm}$ and $560 \mathrm{~nm}$ of 1 as a function of incubation time with GSH (2 mM) in DMSO/PBS solution $(50 / 50, \mathrm{v} / \mathrm{v}, \mathrm{pH}=7.4,10 \mathrm{mM})$ at $37^{\circ} \mathrm{C}$ for $1 \mathrm{~h}$. Concentration of $1: 10.0 \mu \mathrm{M} ; \lambda_{\mathrm{ex}}=490 \mathrm{~nm}$.

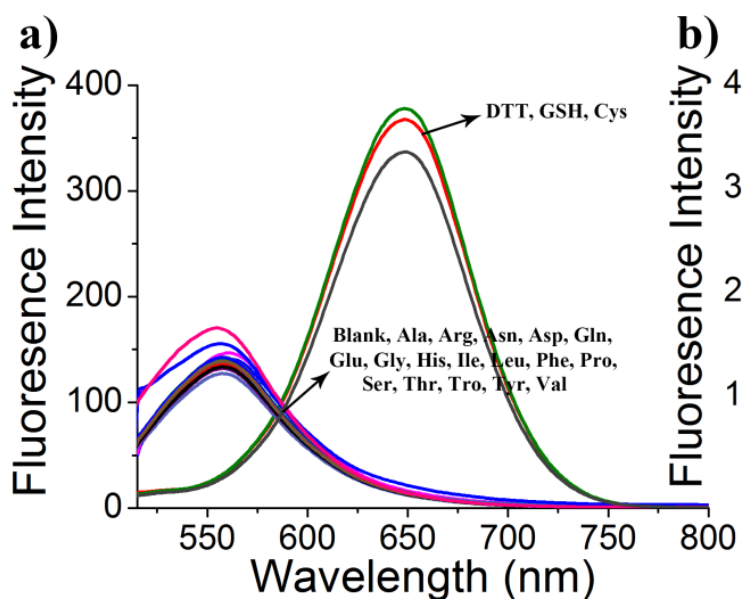

b)

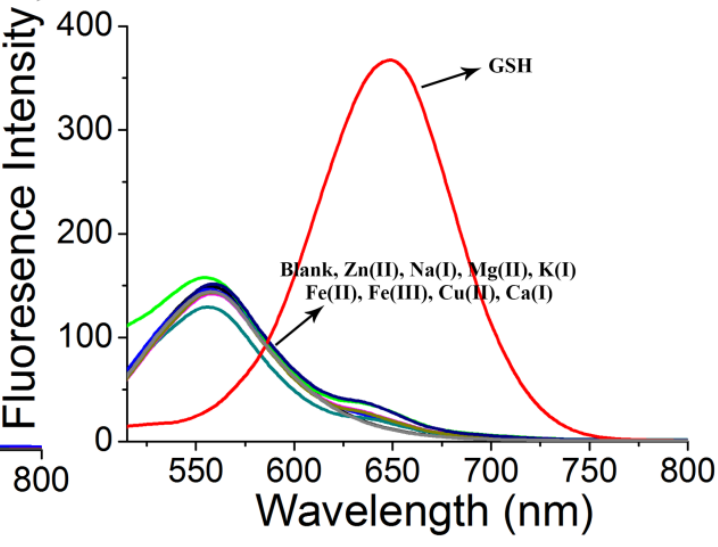

Figure S12. Fluorescence response of $1(10 \mu \mathrm{M})$ upon addition of a) DTT, GSH, Cys, and other amino acids including Ala, Arg, Asn, Asp, Gln, Glu, Gly, His, Ile, Leu, Phe, Pro, Ser, Thr, Tro, Tyr, Val, respectively; and b) GSH and various metal ions in DMSO/PBS solution (50/50, v/v, $\mathrm{pH}=7.4$, $10 \mathrm{mM}$ ). All the concentration used for each analyte is $2 \mathrm{mM}$. Each point was recorded after $1 \mathrm{~h}$ 
incubation at $37^{\circ} \mathrm{C}, \lambda_{\mathrm{ex}}=490 \mathrm{~nm}$.

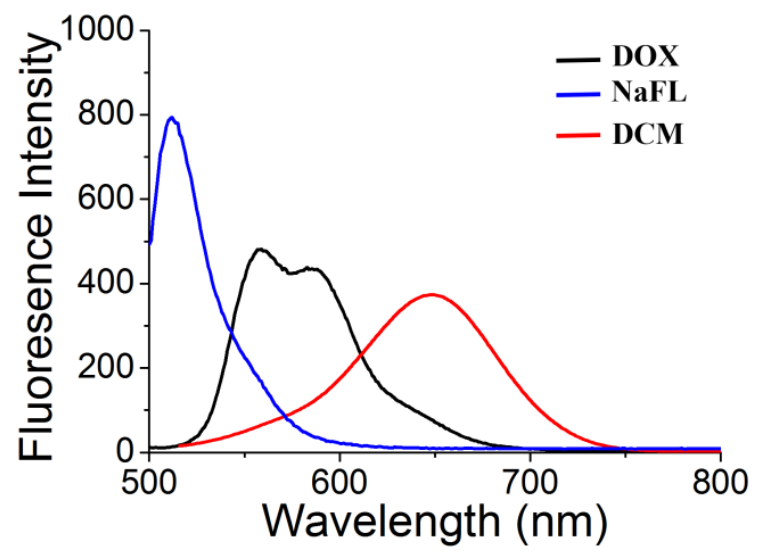

Figure S13. Fluorescence spectra of NaFL $\left(\lambda_{\mathrm{ex}}=488 \mathrm{~nm}\right)$, DOX $\left(\lambda_{\mathrm{ex}}=490 \mathrm{~nm}\right)$, and DCM $(3)\left(\lambda_{\mathrm{ex}}=\right.$ $490 \mathrm{~nm}$ ) in DMSO/PBS solution $(50 / 50, \mathrm{v} / \mathrm{v}, \mathrm{pH}=7.4,10 \mathrm{mM})$. Due to the heavy overlap of the fluorescence spectra of DOX with DCM $\left(\lambda_{\mathrm{em}}=650 \mathrm{~nm}\right), \mathrm{NaFL}$ with maximum emission wavelength at $512 \mathrm{~nm}$ was used instead of DOX to study the release profile of loaded Lac-SS-DCM.

\section{The preparation, characterization and stability of the vesicles}

$0.213 \mathrm{mg}\left(2 \times 10^{-4} \mathrm{mmol}\right)$ of $\mathbf{1}$ was dissolved in $\mathrm{H}_{2} \mathrm{O}(2 \mathrm{~mL})$. The mixture was subjected to ultrasonication for 20 minutes, and then left to stand still overnight to obtain the vesicles, which were characterized by SEM, TEM, and DLS, respectively.

The stability of Lac-SS-DCM in serum was studied with or without $10 \%$ FBS in PBS. The results were showed in Figure S14.

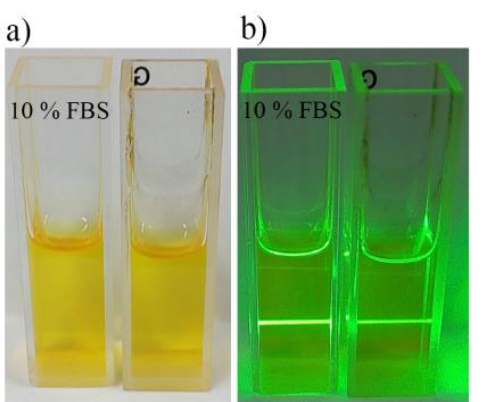

$0 \mathrm{~h}$

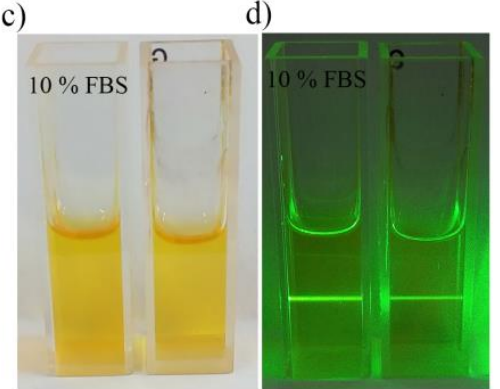

$48 \mathrm{~h}$

Figure S14. The pictures of Lac-SS-DCM in PBS with or without FBS (10\%) at $0 \mathrm{~h}$ and $48 \mathrm{~h}$ : a) and c) viewed under day light; b) and d) viewed under laser. In comparison to the solution of Lac-SS-DCM in PBS, no precipitate was observed in the presence of $10 \%$ FBS and clear Tyndall effect persisted after $48 \mathrm{~h}$, which indicated that the vesicles are fairly stable in serum. 


\section{Analysis of Lac-SS-DCM and Dox-loaded Lac-SS-DCM by dynamic light scattering (DLS)}

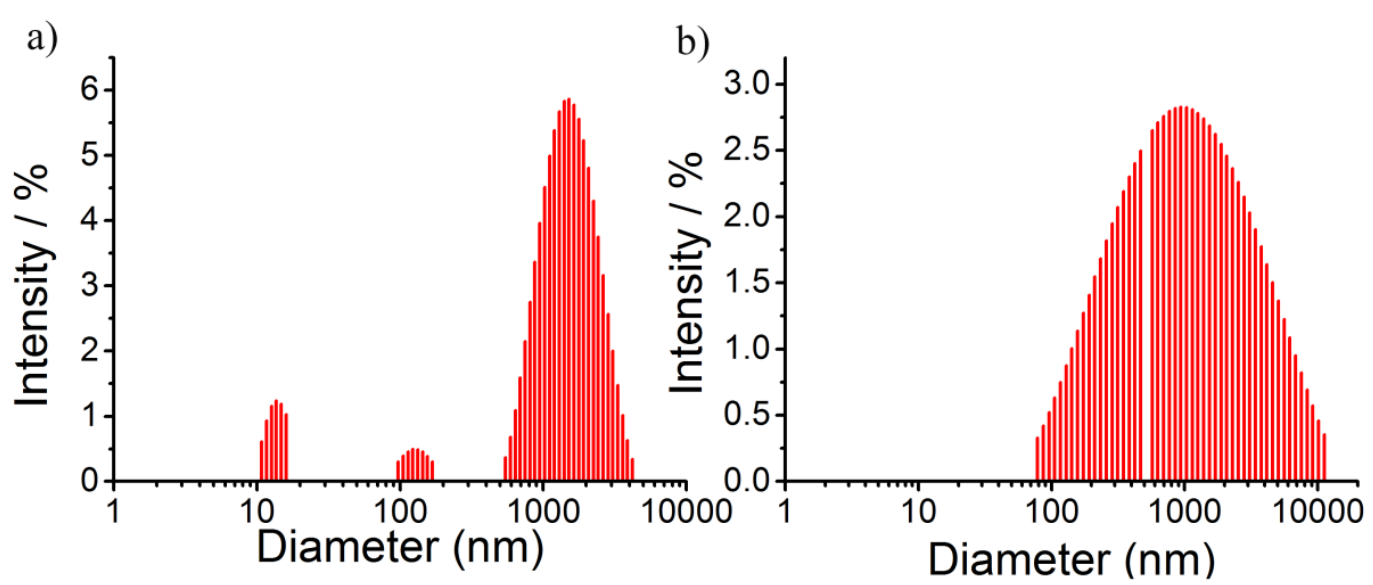

Figure S15. DLS analysis, (a) Lac-SS-DCM after adding GSH, the diameter of most particles increased to micrometer scale; (b) DOX-loaded Lac-SS-DCM after adding GSH. The diameter of most particles increased to micrometer scale. Concentration: $1 \times 10^{-4} \mathrm{M}$.

6. Critical aggregation concentration (CAC) determination of 1

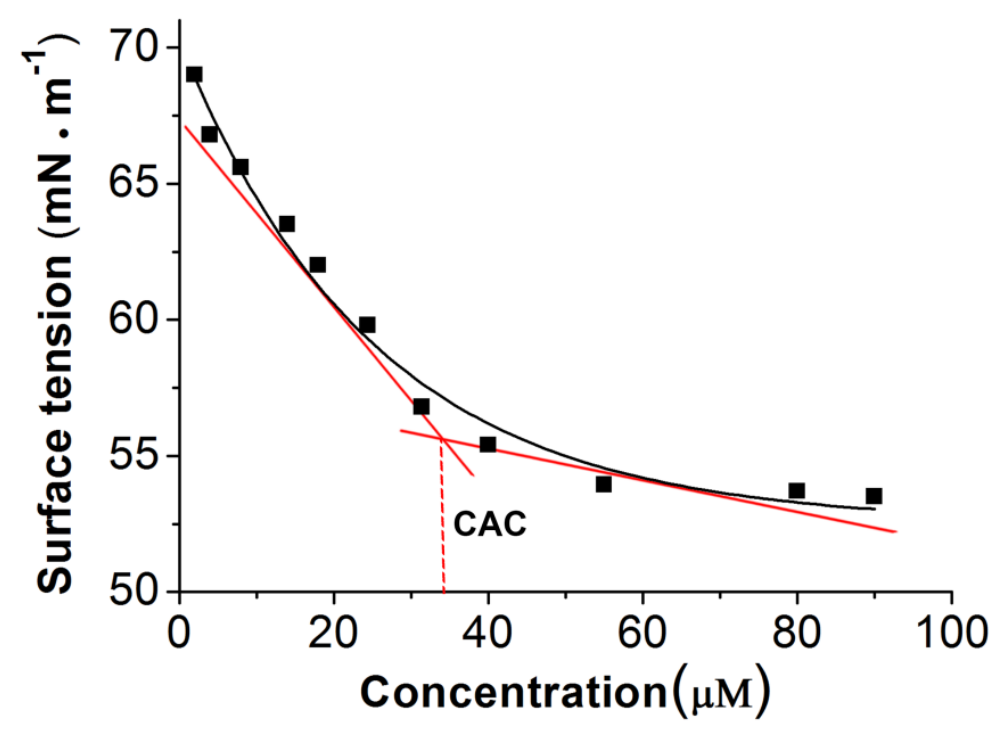

Figure S16. A plot of the surface tension of water vs. the concentration of Lac-SS-DCM. The crossing point of two tangent lines along the curve implies that the CAC is approximately $34 \mu \mathrm{M}$. 


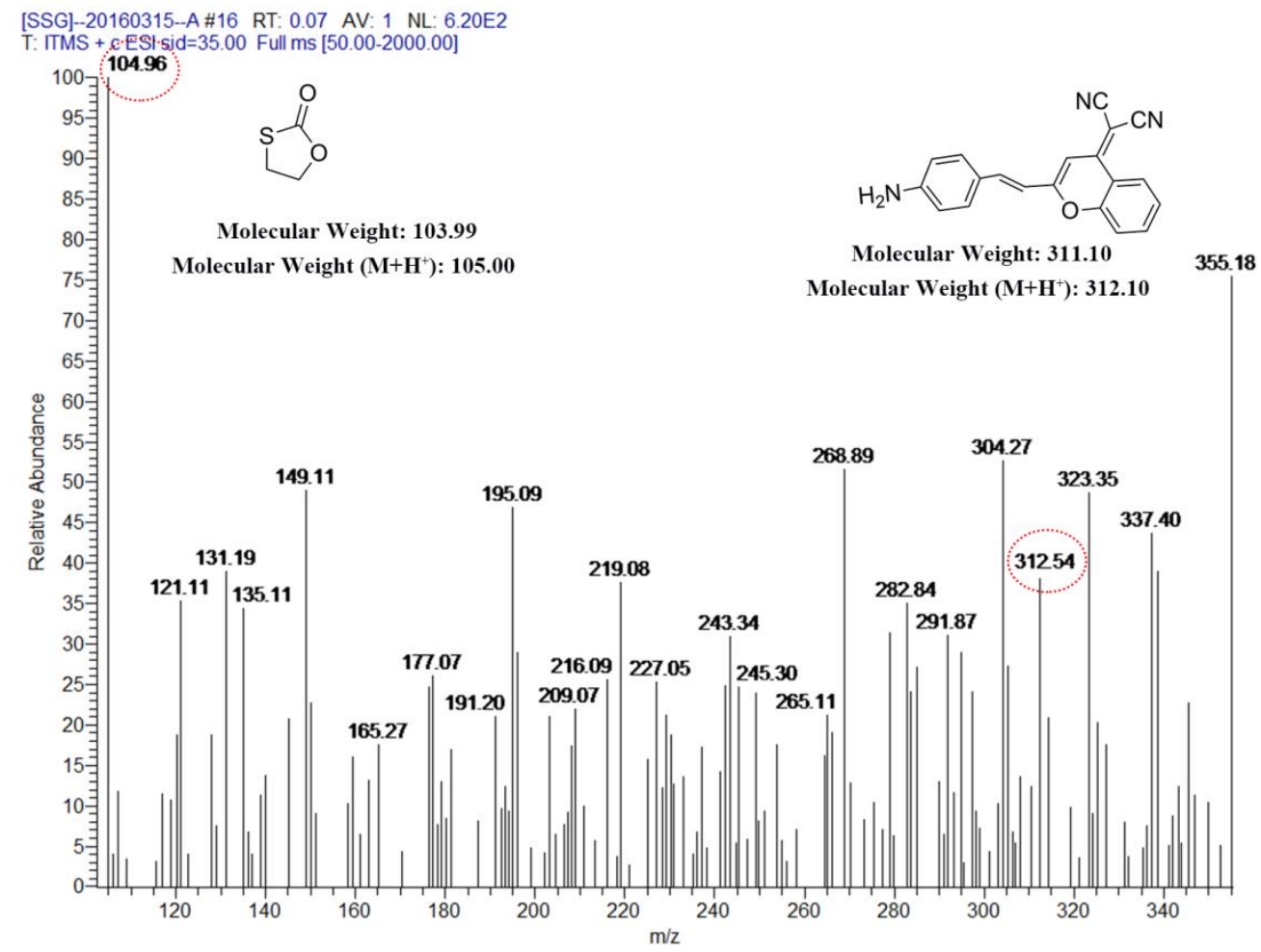

Figure S17. ESI-MS spectrum of a mixture of $\mathbf{1}(10 \mu \mathrm{M})$ with GSH $(1 \mathrm{mM})$ in DMSO/PBS solution $(50 / 50, \mathrm{v} / \mathrm{v}, \mathrm{pH}=7.4,10 \mathrm{mM})$.

\section{The study of release profile 6}

The release profile of dye-loaded Lac-SS-DCM was studied as the following. $0.232 \mathrm{mg}\left(2 \times 10^{-4}\right.$ mmol) of Lac-SS-DCM and $0.0752 \mathrm{mg} \mathrm{NaFL}\left(2 \times 10^{-4} \mathrm{mmol}\right)$ were dissolved in PBS $(2 \mathrm{~mL})$. The mixture was subjected to ultrasonication for 20 minutes, and then left to stand still overnight to obtain the dye-loaded vesicles, which were purified by dialysis (molecular weight cutoff 8000 ) in distilled water until the water outside the dialysis bag exhibited negligible NaFL fluorescence. $2 \mathrm{~mL}$ of dye-loaded Lac-SS-DCM in the dialysis bag was added into $18 \mathrm{~mL}$ of $2 \mathrm{mM} \mathrm{GSH}$ or $10 \%$ FBS at $37^{\circ} \mathrm{C}$. At specified time intervals, the concentration of dye was determined by microplate reader.

\section{DOX loading}

$0.232 \mathrm{mg}\left(2 \times 10^{-4} \mathrm{mmol}\right)$ of Lac-SS-DCM and $0.116 \mathrm{mg}$ DOX $\left(2 \times 10^{-4} \mathrm{mmol}\right)$ were dissolved in PBS ( $2 \mathrm{~mL})$. The mixture was subjected to ultrasonication for 20 minutes, and then left to stand still overnight to obtain the DOX-loaded vesicles, which were purified by dialysis (molecular weight cutoff 8000) in distilled water until the water outside the dialysis bag exhibited negligible DOX fluorescence. The amount of unloaded DOX in the dialysate was quantitatively measured by 
microplate reader. The DOX encapsulation was calculated by the following equations:

Encapsulation Efficiency $(\%)=\left(\mathrm{m}_{\text {Dox-loaded }} / \mathrm{m}_{\text {DOX }}\right) 100$

$\mathrm{m}_{\text {DOX-loaded }}$ and $\mathrm{m}_{\text {DOX }}$ are masses of DOX encapsulated in the vesicles and DOX added, respectively.

\section{The study of GSH-response by flow cytometry ${ }^{7}$}

HepG2 cells were cultured in 1640 medium containing $10 \%$ FBS, $1 \%$ penicillin/streptomycin in $5 \% \mathrm{CO}_{2}$ at $37{ }^{\circ} \mathrm{C}$. $\mathrm{HepG} 2$ cells were seeded in 6-well plates $\left(1 \times 10^{5}\right.$ cells/well $)$ and cultured in complete medium for $24 \mathrm{~h}$. The fresh medium containing $10 \mu \mathrm{M}$ Lac-SS-DCM were added respectively for 3,7 , and $11 \mathrm{~h}$. Then the medium was removed and fresh medium was added for another $1 \mathrm{~h}$. The control group was incubated with fresh medium containing $2.5 \mathrm{mM}$ GSH for another $1 \mathrm{~h}$. Then the cells were harvested and washed for two times with cold PBS and re-suspended in $500 \mu \mathrm{L}$ PBS. Finally, cells were analyzed by a flow cytometer (Beckman Coulter Cytomics Altra).

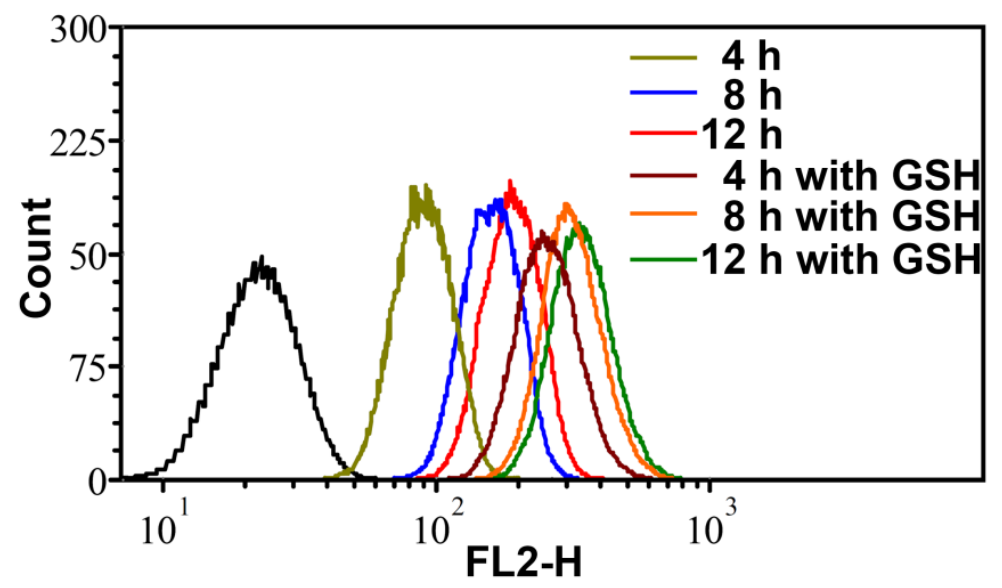

Figure S18. Flow cytometry analyses of cellular uptake of Lac-SS-DCM $(10 \mu \mathrm{M})$ at different time intervals from 4 to $12 \mathrm{~h}$ in $\mathrm{HepG} 2$ cells with and without extra $2.5 \mathrm{mM} \mathrm{GSH}$.

\section{The study of targeting ability by flow cytometry}

HepG2 cells were cultured in 1640 medium containing $10 \%$ FBS, $1 \%$ penicillin/streptomycin in $5 \% \mathrm{CO}_{2}$ at $37{ }^{\circ} \mathrm{C}$. HepG2 cells were seeded in 6-well plates $\left(1 \times 10^{5}\right.$ cells/well $)$ and cultured in complete medium for $24 \mathrm{~h}$. The fresh medium containing $10 \mu \mathrm{M}$ Lac-SS-DCM were added respectively. In contrast, one group was pretreated with lactobionic acid $(2 \mathrm{mg} / \mathrm{mL})$ for $4 \mathrm{~h}$ before the incubation with Lac-SS-DCM. After $4 \mathrm{~h}$, the cells were harvested and washed for two times with cold PBS and re-suspended in $500 \mu \mathrm{L}$ PBS. Finally, cells were analyzed by a flow cytometer 
(Beckman Coulter Cytomics Altra).

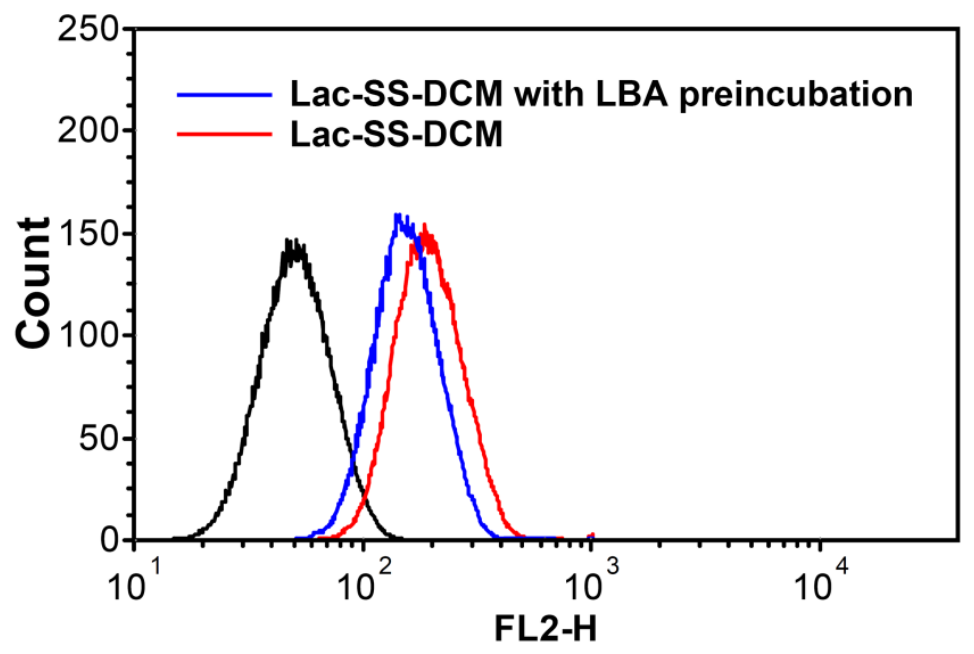

Figure S19. Flow cytometry analyses of HepG2 cells incubated with $10 \mu \mathrm{M}$ Lac-SS-DCM: without (red), or with pre-incubation with LA (blue) for $4 \mathrm{~h}$, respectively.

\section{The study on real-time monitoring by flow cytometry}

HepG2 cells were cultured in 1640 medium containing $10 \%$ FBS, $1 \%$ penicillin/streptomycin in $5 \% \mathrm{CO}_{2}$ at $37{ }^{\circ} \mathrm{C}$. HepG2 cells were seeded in 6-well plates $\left(1 \times 10^{5}\right.$ cells/well $)$ and cultured in complete medium for $24 \mathrm{~h}$. The fresh medium containing $10 \mu \mathrm{M}$ NaFL-loaded Lac-SS-DCM were added for $0.5 \mathrm{~h}, 1 \mathrm{~h}, 2 \mathrm{~h}$, and $4 \mathrm{~h}$ respectively. Then the cells were harvested and washed for two times with cold PBS and re-suspended in $500 \mu \mathrm{L}$ PBS. Finally, cells were analyzed by a flow cytometer (Beckman Coulter Cytomics Altra).

a)

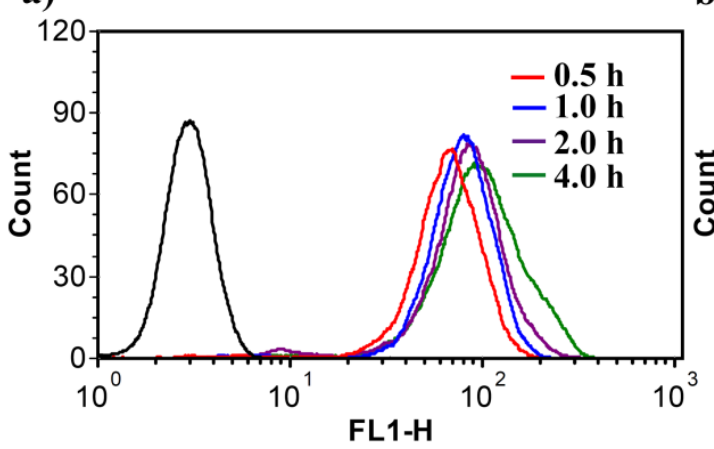

b)

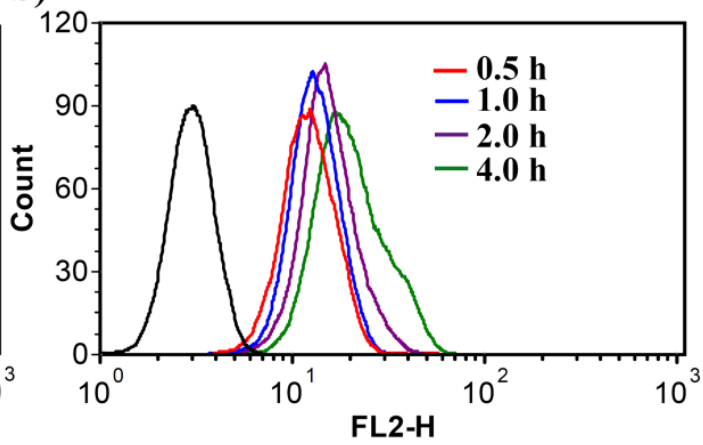

Figure S20. Flow cytometry analyses of HepG2 cells incubated with $10 \mu \mathrm{M}$ NaFL-loaded Lac-SS-DCM from $0.5 \mathrm{~h}$ to $4 \mathrm{~h}$, a) fluorescence of NaFL, b) fluorescence of DCM, respectively.

\section{Cytotoxicity evaluation}


HepG2 cells were cultured in 1640 medium containing $10 \%$ FBS, $1 \%$ penicillin/streptomycin (complete 1640) in $5 \% \mathrm{CO}_{2}$ at $37{ }^{\circ} \mathrm{C}$. 293T and HeLa cells were cultured in DMEM medium containing $10 \% \mathrm{FBS}, 1 \%$ penicillin/streptomycin-in $5 \% \mathrm{CO}_{2}$ at $37{ }^{\circ} \mathrm{C}$. The relative cell viability of different corresponding compounds (Lac-SS-DCM, DOX, or DOX-loaded Lac-SS-DCM) was evaluated in vitro by MTT assay. The cells were seeded in 96-well plates at a density of $5 \times 10^{3}$ cells per well in $100 \mu \mathrm{L}$ complete 1640 or DMEM and grew for $24 \mathrm{~h}$ at $37^{\circ} \mathrm{C}$. Subsequently, cells were incubated with the corresponding compounds at different concentrations for 24,48 , or $72 \mathrm{~h}$, respectively. The cells were washed and the fresh medium containing MTT was added into each plate. The cells were incubated for another $4 \mathrm{~h}$. After removing the medium containing MTT, dimethyl sulfoxide $(100 \mu \mathrm{L})$ was added to each well to dissolve the formazan crystals. Finally, the plate was gently shaken for $10 \mathrm{~min}$ and the absorbance at $490 \mathrm{~nm}$ was recorded with a micro-plate reader.
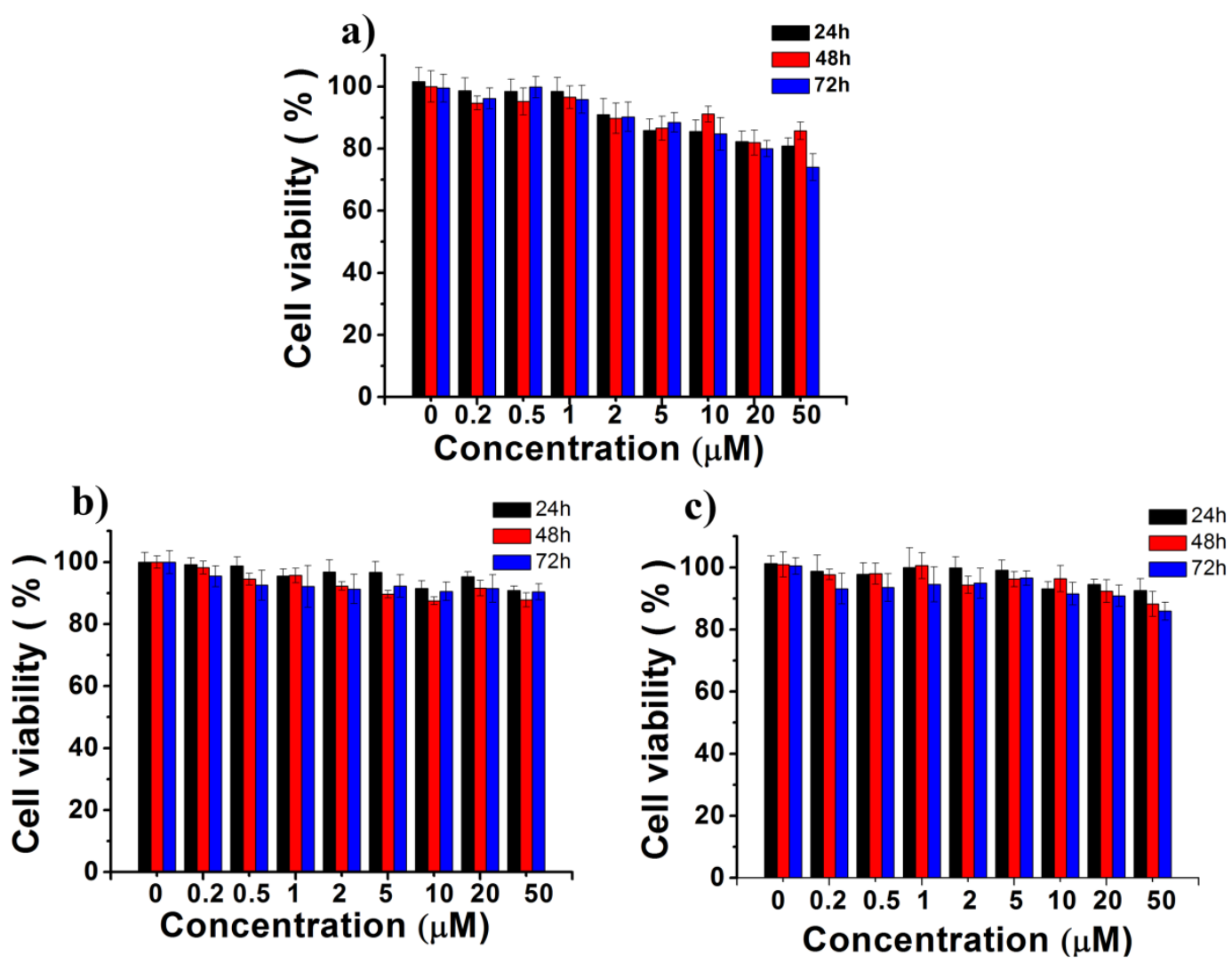

Figure S21. Cell viability of $293 \mathrm{~T}$ (a), HeLa (b), and HepG2 (c) cells incubated with Lac-SS-DCM for 24,48 , and $72 \mathrm{~h}$, respectively. 


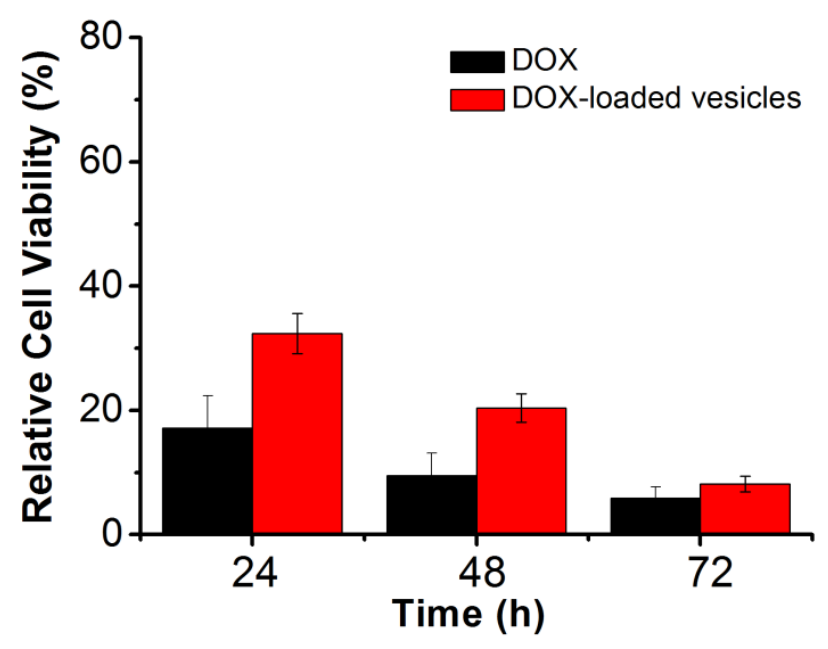

Figure S22. Cell viability of HeLa cells incubated with DOX and DOX-loaded Lac-SS-DCM for 24, 48 , and $72 \mathrm{~h}$, respectively.

\section{Confocal laser scanning microscopy (CLSM)}

HepG2 cells were cultured in 1640 medium containing $10 \%$ FBS, $1 \%$ penicillin/streptomycin (complete 1640) in $5 \% \mathrm{CO}_{2}$ at $37{ }^{\circ} \mathrm{C}$. 293T and HeLa cells were cultured in DMEM medium containing $10 \%$ FBS, $1 \%$ penicillin/streptomycin in $5 \% \mathrm{CO}_{2}$ at $37{ }^{\circ} \mathrm{C}$. For the detailed of dye loaded experiment, HepG2 cells were seeded in $35 \mathrm{~mm}$ plastic bottomed $\mu$-dishes for $24 \mathrm{~h}$, and then the medium was replaced with a fresh one. The cells were treated with NaFL and NaFL-loaded Lac-SS-DCM. After another $4 \mathrm{~h}$ of incubation, the medium was removed, and the cells were washed with PBS buffer ( $\mathrm{pH}$ 7.4) three times. Thereafter, the cells were stained with Hoechst 33342 for 10 min and fixed with $4.0 \%$ formaldehyde at room temperature for $15 \mathrm{~min}$. After $4.0 \%$ formaldehyde was removed and the cells were washed with PBS buffer ( $\mathrm{pH}$ 7.4) three times, the fluorescence images of the cells were captured using a confocal microscope with different channels under a confocal fluorescence microscope (OLYMPUS FV1000). For the details of targeting characterization experiment, HepG2 cells were pre-incubated with LBA for $4 \mathrm{~h}$. For the details of GSH responsive experiment, the cells were incubated with Lac-SS-DCM for $3 \mathrm{~h}$, and then the medium was replaced with a fresh one containing $2 \mathrm{mM} \mathrm{GSH}$ for another $1 \mathrm{~h}$.

\section{References}


1 Sun, W.; Fan, J.; Hu, C.; Cao, J.; Zhang, H.; Xiong, X.; Wang, J.; Cui, S.; Sun, S.; Peng, X., A two-photon fluorescent probe with near-infrared emission for hydrogen sulfide imaging in biosystems. Chem. Commun. 2013, 49, 3890-3892.

2 Jung, D.; Maiti, S.; Lee, J. H.; Lee, J. H.; Kim, J. S., Rational design of biotin-disulfide-coumarin conjugates: a cancer targeted thiol probe and bioimaging. Chem. Commun. 2014, 50, 3044-3047.

3 Wang, C.; Li, Z.; Cao, D.; Zhao, Y.-L.; Gaines, J. W.; Bozdemir, O. A.; Ambrogio, M. W.; Frasconi, M.; Botros, Y. Y.; Zink, J. I.; Stoddart, J. F., Stimulated Release of Size-Selected Cargos in Succession from Mesoporous Silica Nanoparticles. Angew. Chem,. Int. Ed. 2012, 51, 5460-5465.

4 Pires, M. M.; Jean, C., Fluorescence imaging of cellular glutathione using a latent rhodamine. Org. Lett. 2008, 10, 837-840.

5 Hou, Y.; Cao, S.; Li, X.; Wang, B.; Pei, Y.; Wang, L.; Pei, Z., One-Step Synthesis of Dual Clickable Nanospheres via Ultrasonic-Assisted Click Polymerization for Biological Applications. ACS Appl. Mater. Interfaces 2014, 6, 16909-16917.

6 Huang, P.; Wang, D.; Su, Y.; Huang, W.; Zhou, Y.; Cui, D.; Zhu, X.; Yan, D., Combination of Small Molecule Prodrug and Nanodrug Delivery: Amphiphilic Drug-Drug Conjugate for Cancer Therapy. J. Am. Chem. Soc. 2014, 136, 11748-11756.

7 Wu, X.; Sun, X.; Guo, Z.; Tang, J.; Shen, Y.; James, T. D.; Tian, H.; Zhu, W., In Vivo and in Situ Tracking Cancer Chemotherapy by Highly Photostable NIR Fluorescent Theranostic Prodrug. J. Am. Chem. Soc. 2014, 136, 3579-3588. 